\title{
Translanguaging as Inclusive Pedagogical Practices in English-Medium Instruction Science and Mathematics Classrooms for Linguistically and Culturally Diverse Students
}

\author{
Kevin W. H. Tai ${ }^{1}$ (D) \\ Accepted: 15 July 2021/Published online: 15 November 2021 \\ (C) The Author(s) 2021
}

\begin{abstract}
In English-medium instruction (EMI), English-as-a-second-language students will learn all/some subjects through English. Although there are a considerable number of studies which explore classroom interaction in Hong Kong (HK) secondary EMI schools, few studies have investigated EMI lessons which involve South Asian ethnic minorised students. These students share different linguistic and cultural backgrounds and they may not share a common first language with the teacher and other classmates. This study conducts a multimodal conversation analysis of science and mathematics lessons at a HK EMI secondary school, triangulated with interview data, in order to explore how the EMI teacher mobilises various resources to make discipline-specific knowledge accessible and cater for the different needs of all students in the classroom. This study argues that the process of enacting inclusive practices is a process of translanguaging which requires the EMI teacher to mobilise various available multilingual and semiotic resources and draw on what students know collectively for transcending cultural boundaries from the students' everyday culture to cultures of school science and mathematics.
\end{abstract}

Keywords Translanguaging · Multimodal conversation analysis · English-medium instruction · Inclusion $\cdot$ Language minority students $\cdot$ Linguistic and cultural diversity

\section{Introduction}

Adopting English-as-a-second/foreign-language other than the home language as the mediumof-instruction in academic subjects, such as mathematics and science, is a growing phenomenon in many countries (Lo, 2014; Lo \& Lin, 2018). It is widely acknowledged that the

Kevin W. H. Tai

kevin.tai.19@ucl.ac.uk

1 UCL Centre for Applied Linguistics, UCL Institute of Education, University College London, London, UK 
language of science and mathematics involves different subject-specific technical terms and tends to be more analytical in nature, as it is used to express abstract concepts, logical relationships and universal phenomena (see 'Issues in Implementing EMI' section). A perpetual concern in English-medium instruction (EMI) has been focusing on how mathematics and science teachers can balance the teaching of content and the second language (L2), particularly when the students are still developing their L2 scientific and mathematical literacies and their L2 English proficiency and concurrently learning abstract and unfamiliar discipline-specific knowledge (Lo, 2015). Specifically, what can teachers do with the languages in the students' linguistic repertoire that are not the school's medium-of-instruction? How can teachers employ multilingual and multimodal practices so that students can be inducted into the discursive and semiotic practices of the discipline? Moreover, how can EMI science and mathematics teachers bridge the differences between the students' everyday life culture and the cultures of school science and mathematics in order to promote the learning of science and mathematics?

Translanguaging has been considered as a useful pedagogical resource for promoting student inclusion in multilingual classrooms (e.g. Garcia \& Li, 2014; Woodley, 2016). Inclusive pedagogy has a high priority in educational policy in different countries and teachers are expected to handle in practice increasing learner diversity and the demands for promoting equal opportunity and social inclusion in the classrooms (e.g. Ainscow et al., 2006; Miles \& Singal, 2010). Such diversity can be shown in any classrooms of learners and studies have illustrated the complex ways in which disabilities, gender, language barriers, ethnicity and social class can influence a student's opportunity to succeed or fail in the educational system. The notion of translanguaging celebrates the multilingual's capabilities in drawing on their diverse and holistic multilingual, multimodal, multi-semiotic and multisensory resources for enabling the meaning-making processes. From a translanguaging perspective, this emphasises the need to look beyond the conventional conceptualisation of named languages as different codes of speech and writing, specifically, the embodied and multimodal aspects of communication ( $\mathrm{Li}, 2018 ; \mathrm{Li}, 2020)$. Recent research on EMI classroom interaction has examined the role of taking advantage of the affordances of translanguaging as a pedagogical resource to support content teaching and learning in science classrooms (e.g. Lin, 2006; Lin \& Wu, 2015; Mazak \& Herbas-Donoso, 2015; Wu \& Lin, 2019). These studies typically focus on classroom settings where the students share a common first language (L1) and cultural background with the teacher and other classmates. Little attention has been paid to how EMI science and mathematics teachers conduct teaching in linguistically and culturally diverse EMI classrooms which may involve minority ethnic children of immigrant backgrounds.

Based on science and mathematics classroom data collected from a Hong Kong (HK) EMI secondary school which has a significant number of South Asian (SA) ethnic minorised students, this paper adopts translanguaging as an analytical perspective to analyse EMI science and mathematics classroom interactions. The study will first analyse a unique case which involves an EMI teacher teaching both SA ethnic minorised students and local and overseas Chinese students in the same EMI science classroom. It will then analyse how the same EMI teacher teaches an EMI mathematics class with only SA students in order to explore how different translanguaging strategies are employed in different classrooms of the HK EMI secondary school. SA students are referred to as 'Non-Chinese-speaking Students (NCSS)' in HK since they speak home languages other than Chinese. They come from diverse ethnic and cultural backgrounds (e.g. Pakistani, Nepalese and Indian) and have very mixed previous home literacy learning experiences. So far, limited studies have been conducted on their 
learning experience (e.g. Connelly et al., 2013; Ku et al., 2005) and there is a growing body of studies that have been done to develop pedagogical approaches and curriculum materials to support them to learn Chinese as an L2 (Tsang, 2021; Tsung et al., 2012). To date, there is a lack of research that has developed pedagogical strategies to support teachers in facilitating SA students' content learning process in EMI science and mathematics classrooms (Lin \& He, 2017). Particularly, the EMI teacher, who teaches the mixed EMI science class in this case, also needs to cater to the local and overseas Chinese students' linguistic needs and their progress in learning content knowledge in the classroom. It is often expected that students in the EMI classrooms will use English version of the textbooks and take the school examination in English. Nevertheless, in this particular science class, the Chinese students use Chinese version of the science textbooks in the EMI science classroom and they will take the Chinese version of the school-based science examination paper.

Hence, this study aims to offer an alternative view of inclusive pedagogy by linking it to translanguaging and its emphasis on the mobilisation of multiple multilingual and multimodal resources by the EMI science and mathematics teacher. This paper provides empirical evidence in order to illustrate how translanguaging practices can potentially be deployed as an inclusive pedagogy in the EMI science and mathematics classrooms to engage linguistically and culturally diverse students for content and language learning and promote social inclusion in the classroom. In this study, a semi-structured interview with the EMI teacher, who is also a $\mathrm{SA}$, and classroom video-recordings form the main database. Multimodal conversation analysis (MCA) is carried out on the classroom interactional data in order to examine how meaning-making is constructed multilingually and multimodally. The analyses of the classroom interactional data are triangulated with the teacher's interview data in order to understand how the teacher's use of multilingual and multimodal resources are shaped by various sociocultural and contextual factors.

\section{Medium-of-Instruction in Hong Kong}

The choice of medium-of-instruction in the educational system has been a highly controversial issue for decades in HK, where the majority of the citizens speak Cantonese as their L1. In general, the majority of primary schools in HK adopt Chinese-medium instruction (CMI) for most content subjects and English is taught as a separate core subject. At the tertiary level, universities in HK use EMI due to the need to improve global outlook, cater for a large number of international students and improve employability among students (Lo \& Lin, 2018). While the medium-of-instruction policies are broadly set for primary and university education, medium-of-instruction policy at the secondary level has gone through immense changes (Poon, 2010). HK's secondary schools have witnessed three key stages in the development with regard to medium-of-instruction policies, including (1) the laissez-faire policy prior to 1994; (2) the compulsory CMI policy during 1998-2010 which allowed 114 secondary schools to use EMI to teach content subjects while the remaining 307 schools were mandated to use CMI; and (3) the fine-tuning medium-of-instruction policy since 2010. The policy is in part responding to the parental desire for their children to be educated in EMI settings. Under the fine-tuning policy, secondary schools are allowed to offer EMI classes, partial-Englishmedium classes (i.e. one or two subjects conducted in EMI) and/or CMI classes. CMI schools have the autonomy in selecting their medium-of-instruction for content subjects if they have met certain criteria (Education Bureau, 2009). 
As Tollefson and Tsui (2014) argue, the debate of adopting EMI in secondary schools ignores the fact that such a monolingual rule offers limited opportunities for social interactions because teachers in EMI classes tend to adopt the lecture format to teach the content. Lo's (2014) offers empirical evidence which supports Tollefson and Tsui's (2004) argument. Lo's findings have shown that L2 learning opportunities can vary in different EMI content subjects. According to Lo (2014), mathematics and science lessons in HK do not favour classroom discussion between the teacher and the students since these lessons are often treated as solving problems with set formulas and calculation procedures. Therefore, students seldom have the chance to contribute responses in classroom interactions. Nevertheless, the study only focuses on EMI classrooms in HK where both the teachers and students share the same L1 and cultural backgrounds. There is a lack of research that explores the reality of the HK EMI classroom with teachers and students who share different linguistic and cultural backgrounds (see 'Issues in Implementing EMI' section for more empirical studies on EMI science and mathematics classrooms in $\mathrm{HK}$ ).

\section{Inclusive Education}

The term 'inclusive education' has taken on various meanings in different contexts. It is often employed in the UK to refer to practices within special needs schools (Surgeon, 2007). Slee (2004) has suggested that the idea of inclusive education is being employed to mean multiple things and these different interpretations of inclusive education reveal that there is conceptual confusion regarding this issue, but possibly also that it necessarily has different meanings, depending on contextual concerns. In some contexts, such as the UK, inclusive education is no longer related to disability or special needs but rather than school attendance or discipline (Ainscow et al., 2006). Ainscow et al. (2006) have developed a framework of six ways of thinking about inclusion, including inclusion as a response to disciplinary exclusion, as a principled approach to education and society and as a concern with disabled students and others categorised as having special educational needs (SEN). Fundamentally, the essence of inclusion is a process of promoting social justice and fighting exclusion in schools and communities and being aware of whatever threats to equity arise (Salend \& Garrick-Duhaney, 1999). A number of researchers have studied the impact of inclusive arrangements on students' learning experiences. For instance, Salend and Garrick-Duhaney (1999) argue that adopting the practice of inclusion in classrooms with students with disabilities can improve their academic achievement, increase peer acceptance and higher self-esteem.

The manifestation of inclusion in mathematics and science education is typically foregrounded with related notions including equity and participation (e.g. Foyn et al., 2018; Hand, 2012). In a review conducted by Roos (2019), she examines how the notion of 'inclusion' is used in mathematics education research. She particularly focuses on analysing the discourse of inclusion in mathematics from societal and classroom perspectives. The findings reveal that the discourse of inclusion from a societal perspective defines inclusion in regard to equity in mathematics education, making mathematics education available for all students, including and excluding students, valuing diversity and equity in gender, tests and ethics. On a classroom level, it is found that the notion of inclusion is defined as student engagement, maximising opportunities for student participation and acknowledging various students' learning needs. Roos argues that mathematics classroom research studies tend to focus on describing the meaning of inclusion as student's participation and involvement. In a 
mixed-method study in year 10 multi-ethnic mathematics classrooms in New Zealand, Averill (2012) explores the teachers' caring behaviours in mathematics classrooms (e.g. creating opportunities for students to work together, using inclusive language and acknowledging student responses). Averill reports the findings on 100 observed lessons and he argues that 'the lessons exhibiting the most caring teacher behaviours and practices were those with greatest student engagement (i.e. highest levels of on-task student behaviours) and the most student-initiated interactions (related and unrelated to mathematics)' (p. 121). Moreover, Piliouras \& Evangelou, 2012) study how science teachers utilise various strategies to help migrant students to move from their everyday culture into the culture of school science as a way of promoting scientific literacy. The analysis of the science classroom interactions reveals that the teachers use appropriate cross border strategies for assisting students to cross smoothly from their culture to the culture of school science. These strategies include eliciting students' ideas about scientific phenomena, encouraging students to think like scientists, facilitating students' participation in discussions and bridging between colloquial and scientific language. These studies (e.g. Averill, 2012; Piliouras \& Evangelou, 2012) illustrate that inclusive education is manifested in the science and mathematics classrooms which depends on the disciplinary context and the related discursive practices.

To date, there is very little literature on inclusion in science and mathematics classroom interactions. In this paper, inclusion is understood in its broader sense as a philosophy of acceptance where all individuals are treated with respect. Hence, inclusion extends beyond special educational needs and disabilities and it is considered as a process that is concerned with everyone. It emphasises the importance of taking accounts of students' varied needs in order to bring equal access to educational opportunities and full participation by all students in school settings. The notion of participation is central in inclusive pedagogy and it emphasises the role of the teachers' pedagogical practices in supporting all students' learning processes. Trussler and Robinson (2015) conceptualise whole-class approach as a key inclusive practice for catering to different needs of all students to facilitate their learning success. This requires the teacher to have all students in mind rather than the majority or the minority when planning classroom activities, so that it can make learning more accessible for all students.

In the EMI context, while it is important to construct opportunities for English language use in EMI lessons for promoting English acquisition, it is equally important to encourage fluid language practices and allow teachers and students to draw on their full linguistic and semiotic repertoires to make the content knowledge and L2 academic registers accessible to all students. These resources, including L1, L2, everyday and academic, oral and written registers, gestures and other modalities, are important communicative resources that teachers and students can draw upon for supporting teaching and learning in EMI science and mathematics classrooms. It is vital to note that the aim of bi/multilingual education is not to replace students' multiple multilingual and multimodal resources with school-recognised named languages ( $\mathrm{Li}, 2018)$. It is necessary for teachers to acknowledge that these different communicative means constitute a holistic repertoire of the student that is constantly expanding for communication (Garcia \& Li, 2014). This, in turn, can potentially alleviate the language barriers to learning academic concepts, counteract students' linguistic insecurity and promote students' participation in classroom discussions. In this paper, I argue that translanguaging can encourage EMI teachers to mobilise available resources and make strategic choices among the resources in order to legitimise his/her inclusive classroom practices at a whole-class level. In particular, such approach of conceptualising inclusive pedagogy as mobilisation of resources for teaching is informed by the notion of translanguaging, which will be discussed in the next section. 


\section{Translanguaging as an Inclusive Pedagogical Practice}

The Welsh-inspired term translanguaging was coined to describe a pedagogical practice of switching between different input and the output languages in bilingual classrooms (Williams, 1994). Li (2018) further shapes the concept of translanguaging as a process of knowledge construction which involves drawing on various multilingual resources (i.e. not only different languages and dialects but also styles, registers and other variations in language use) and different multimodal resources (e.g. switching between speaking and writing, or coordinating gestures, body movements, facial expressions and visual images). The translanguaging perspective differs from the traditional view of code-switching. The notion of code-switching perceives each language as a separate linguistic system and code-switching analysis typically starts with the identification of different linguistic codes during discursive exchanges. It then follows either a functional analysis in order to understand the process of integrating various grammatical systems into a coherent unit and the functions of shifting from one language to another at a specific point of the communicative episode. However, a translanguaging perspective would interrogate the traditional divides between the linguistic, the paralinguistic and the extralinguistic aspects of human communication as nonsensical. Emphasising the transformative nature of translanguaging practices, Li (2018) proposes the notion of 'translanguaging space' where multiple multilingual, multimodal and multisensory repertoires interact and co-produce new meanings. The notion of translanguaging space is different from other conceptualisations of language since translanguaging space aims to go beyond the boundaries between spatial and other semiotic resources since it views spatial positioning and display of objects as semiotic and socially meaningful. In other words, the notion of translanguaging reinforces the theoretical assumption associated with multimodality which considers 'all interactions are multimodal' (Norris, 2004: 1). Speakers combine features of their verbal language with semiotic resources when interacting with others as part of an integrated communicative repertoire (Tai and Li Wei, 2020, 2021a, 2021b, 2021c; Ho \& Li, 2019).

Garcia and $\mathrm{Li}$ (2014) propose that translanguaging practices are transformative as it has the potential to remove the hierarchy of languages in a society that are seen as more valuable than the others. They argue that translanguaging is viewed as a new language practice which allows the flow of fluid discourses in a different social, cultural and political context and provides a voice to speaker's linguistic identities that has been suppressed within the fixed linguistic ideology adopted by nation-states. Deploying students' full linguistic repertoire in the classroom has roots in inclusive education, culturally relevant and culturally responsive teaching and multicultural education as argues by Ladson-Billings (1995). Teaching for equity and social justice requires teachers to integrate students' full linguistic resources into learning opportunities and building on students' linguistic and cultural funds of knowledge (Garcia \& $\mathrm{Li}, 2014)$. This can potentially give voice to students who are silenced by the monolingual policy in bi/multilingual classrooms. Hence, translanguaging can be a mechanism for promoting to provide equity and social justice. Translanguaging encourages teachers and students to deploy their available multilingual and multimodal resources as a way to challenge the traditional configurations, categories and power structures, equalise the hierarchy of languages in the classrooms and allow students' full participation in constructing new meanings and new configurations of language practices. By doing so, it creates a translanguaging space for meaning-making and social justice. 
A growing body of work in multilingualism has revealed that translanguaging is not only a multilingual and multimodal practice, but it can also offer pedagogical and interpersonal functions in the multilingual classrooms (Tai and Li Wei, 2020, 2021a, 2021b, 2021c; Garcia \& Li, 2014). For instance, Woodley (2016) illustrates how translanguaging in a highly diverse elementary classroom promotes participation. By constructing multilingual resources, including labels and signs and posters in multiple languages, offering select home language translations, grouping students with the same L1s and encouraging language comparisons when explaining new vocabulary items, the teacher successfully leverages students' multilingualism while communicating with his students in English. However, the findings of this study are generated from the teacher's interview data and field notes. Without a detailed analysis of the classroom discourse, it is unclear how does translanguaging enable inclusion in multilingual classrooms. Hence, this paper aims to address this gap by examining how translanguaging can be used as an inclusive pedagogy in EMI science and mathematics classrooms.

\section{Issues in Implementing EMI}

As Macaro (2018: 19) suggests, EMI is defined as 'the use of the English language to teach academic subjects (other than English itself) in countries or jurisdictions where the L1 of the majority of the population is not English'. Based on this view, it is considered necessary for EMI teachers to limit their L1 use in order to create an English-speaking environment for students to acquire complete knowledge of English (Pun \& Macaro, 2018). The input hypothesis has traditionally dominated SLA literature which has offered the main rationale for the monolingual policy for employing only English (i.e. the target language) in EMI classrooms (Lin, 2013; Lo, 2015; Macaro 2018). However, one important issue encountered by EMI teachers in HK is the wide gap between students' English proficiency and cognitive levels (Lo and Lin, 2018). In EMI classrooms where some students' English proficiency levels do not reach the threshold level, they are often prevented from mastering the academic knowledge which is often abstract and cognitively more difficult for students (Lo, 2014).

As systemic functional linguists (e.g. Martin et al., 2020; O'Halloran, 2000; Schleppegrell, 2004) suggest, different registers of different academic subjects can provide different kinds of L2 input for learners. For instance, the contents of science and mathematics are more technical and abstract. The language involved is often analytical in nature since it is employed to articulate abstract concepts (O'Halloran, 2000). It has been observed that several common genres in science, including procedures, procedural recount (e.g. laboratory reports) and explanation, are typified by scientific technical terms, complex noun groups and passive voice (Lo \& Lin, 2019; Schleppegrell, 2004). In terms of mathematics discourse, it is characterised by the prevalence of subject-specific technical terms, use of mathematical symbols, high lexical density, complex noun groups and the use of nominal groups (i.e. noun groups) for referring to mathematical concepts (Schleppegrell, 2007). For instance, action verbs (e.g. estimate, expand, convert, simplify and evaluate), prepositions (e.g. ahead, about and over) and conjunctions (e.g. assume, given, let and take) have specific operations. The meanings of these action verbs in mathematics discourse can be quite different from 
everyday language use. Hence, if science and mathematics teachers simply apply the sink-or-swim practices, otherwise known as immersion, without offering explicit L2 teaching, it would create insurmountable problems to students' learning as students will not be able to understand the discipline-specific language that is necessary for expressing their content knowledge. This is particularly true in contexts where students may not have been sufficiently prepared for EMI regarding their L2 English proficiency.

EMI education also has a social justice concern, which is related to the survival of minority languages and the linguistic rights of the students. On the one hand, the implementation of the EMI policy has shaped parent's linguistic ideology that they look down upon their local languages, downgrading their value in educational practices. In the context of HK, there is a strong preference for EMI schools by parents and other stakeholders due to the belief that EMI schools can effectively facilitate English acquisition (see 'Medium of Instruction in Hong Kong' section). Hence, the acquisition of English is seen as a tool for global communication and for supporting minoritised communities from their socioeconomic struggles in other contexts (Haider, 2019). Consequently, by imposing a monolingual medium-of-instruction in the classroom, parents and other stakeholders believe that using local languages in EMI classrooms means taking away the students' time from acquiring the L2. Such a monolingual rule has a serious threat to teachers' and students' attitudes towards local languages and, importantly, to their sense of linguistic and cultural identities. For instance, in Haider's (2019) study, the EMI graduates in Pakistan value English highly followed by Urdu, the national language. The ideological dominance of English and Urdu pushes local languages to be deployed only for low-level everyday matters and they are deemed as inappropriate for academic and literary purposes. Haider argues that such a situation may endanger the local languages and affect the multilingual status of the country.

In recent years, the theoretical framework of translanguaging has attracted the attention of EMI researchers due to the 'multilingual turn' in bi/multilingual education (May, 2014), calling for a more nuanced ethnographic understanding of speakers' complex, multilingual and multimodal repertoires in their construction of meanings. This has encouraged EMI researchers to analyse the tension between the practice of using English as the only medium-of-instruction and the reality of multilingual students speaking multiple languages (Lin, 2019). A recent ethnographic study by Lin and He (2017) investigates how an EMI science teacher uses translanguaging as a pedagogical strategy to motivate South Asian ethnic minorities to draw upon their multilingual repertoires in a year 9 HK EMI science classroom. The findings indicate that although the teacher and learners come from different linguistic and cultural backgrounds, their willingness to learn from one another create a space where learners are motivated to use the L2 and develop their linguistic repertoires. Lin and $\mathrm{Wu}$ (2015) investigate how learners use translanguaging to actively construct meaning and display understanding in a year $8 \mathrm{HK}$ EMI science classroom. Based on their analysis of a 5-min interaction, the findings indicate that by allowing a low-proficiency learner to answer the teacher's response in Cantonese, this creates an opportunity for the learner to display her scientific knowledge. Tai and Li Wei (2021a) study investigates the role of playful talk in constructing translanguaging space in a HK EMI mathematics classroom where the teacher and students share the same L1 and cultural background. The analysis has shown that teacher's personal belief, history, sociocultural and pedagogical knowledge play a role in motivating the mathematics teacher to translanguage during classroom instruction. 
It can also be argued that translanguaging can enable inclusive practices in EMI mathematics and science classrooms through transcending cultural boarders from everyday culture to the culture of school science and mathematics. Phelan et al. (1991) argue that culture can be conceptualised as the 'norms, values, beliefs, expectations, and conventional actions' of a group. Cobern and Aikenhead (1998) develop the idea that school science and mathematics as distinctive cultures that can support or disrupt the students' worldview. The multiple aspects of culture, including the culture of the student's home, school or classroom, differ from the different social groups within a community, such as the students' local culture, from the culture of school science and mathematics. Students will soon notice that the world of school science and mathematics 'is another culture with which he/she has to interact with, bringing with him/ her the other baggage of cultures he/she already carries' (Jegede \& Aikenhead, 1999: 2). Aikenhead (2001) suggests that when students learn science, they need to go beyond a cultural boundary from their everyday life culture into the culture of a science classroom. Aikenhead conceptualises the transition from students' life-world culture and school science experience as a cultural border crossing. When the culture of science is in harmony with the student's everyday culture, then science instruction will support the student's worldview, which will lead to enculturation. Nevertheless, if the culture of science differs from the student's lifeworld, then the science instruction will disrupt the student's perception of the world which will lead to assimilation. In order to develop a culturally sensitive and inclusive instruction, it is vital for teachers to understand how cultural border crossing occurs and how they can provide assistance for students to move between cultural borders. Tai and Li Wei (2020) have demonstrated that the ways an EMI mathematics teacher construct an integrated translanguaging space by bringing the student's everyday life space into the EMI institutional learning space in order to turn the mathematics classroom into a lived experience. This allows the teacher and students to bring their funds of knowledge to the forefront which makes the mathematical knowledge more relatable and relevant to the student's everyday life experience. In this paper, it is argued that translanguaging enables an EMI mathematics and science teacher to induct the discursive and semiotic practices of the science and mathematics disciplines to the students which can include all students in the learning of science and mathematics by assisting students to transcend cultural borders from their everyday life culture to the cultures of science and mathematics.

It is noticeable that a considerable number of EMI or content-and-language-integratedlearning (CLIL) studies on science and mathematics classrooms (e.g. Mazak \& HerbasDonoso, 2015; Sahan \& Rose, 2021) has conceptualised translanguaging as practices which indicate the movement among linguistic repertoires. Tai and Li Wei, (2020, 2021a, 2021b, 2021c), Lin and Wu's (2015) and Lin and He's (2017) studies are rare examples of employing multimodal analysis in capturing translanguaging as a multilingual and multimodal resource for promoting learning in EMI mathematics and science lessons. Since there is limited research studying SA students' mathematics and science learning in EMI contexts (Lin \& He, 2017) and there is a lack of research studies that explores inclusive practices in science and mathematics classrooms, this study fills in the research gaps and adopts translanguaging as an analytical perspective in order to explore how the EMI science and mathematics teacher strategically mobilises various multilingual and multimodal repertoires to facilitate students' understanding of the discipline-specific knowledge and develop students' ways of thinking within the mathematics and science disciplines in linguistically and culturally diverse classrooms. 


\section{Methodology}

\section{Participating School and Students}

The school is classified as a designated school which receives funding from the Education Bureau to deliver a mediated Chinese curriculum for helping SA students in learning Chinese as an L2. This school has a typical high concentration designated school as the school has been educating SA students for an extensive period of time. The school principal is well-known for promoting multilingual and multicultural education (e.g. Arnow, 2001; Fowers \& Davidov, 2006) at his school through giving public lectures and presenting research findings in academic conferences. The majority of the students are from Southeast Asia and the school has recruited a small group of local and overseas Chinese students. The school provides education from secondary one to six based on the curriculum guides set by the HK Education Bureau. The school offers EMI classes to SA students so that they can learn the academic subjects through English. The school adopts a monolingual EMI policy where the teacher and SA students can only speak English during EMI lessons. The school also offers a mixed class in each grade which aims to provide an interactional space where both SA students and Chinese students can learn content subjects together in the same class. This can potentially create a multilingual learning environment for all students where they can engage in intercultural communication. Students who are in the mixed classes can take the school-based content subject examinations in either English or Chinese. They can also choose to buy their textbooks in either Chinese or English. Although the two groups of students are preparing for the examinations in either English or Chinese, the main medium-of-instruction of the mixed classes is in English (L2) since $80 \%$ of the students in these classes are SA students. Nevertheless, the school adopts a flexible language policy which allows teachers and students in the mixed EMI classes to speak Chinese (Mandarin or Cantonese) in order to ensure all students can understand the content knowledge. Such an EMI classroom has not been documented in the literature before and this is a unique case of a mixed EMI classroom which entails two groups of students who share different linguistic and cultural backgrounds, use different language versions of the textbooks during the lessons and prepare for the different language versions of the internal school examinations.

\section{Participating Teacher}

The EMI teacher in the present study has at least 7 years' experience in teaching mathematics and science in English. He serves as the Heads of Mathematics and Science departments at the school. The teacher was interested in the concept of translanguaging and research on EMI education and he wished to learn more about it. Therefore, he was willing to participate in this study when I initiated it. He is a Pakistani and he has lived in HK for most of his lifetime. He is an L1 speaker of Urdu and Punjabi. Arabic, English, Cantonese and Mandarin are his additional languages. He previously attended EMI schools for his early childhood, primary and secondary education. Although English is his L2, he considers English as his most proficient language, after Cantonese, Urdu and Punjabi. He acknowledges that he has limited proficiency in Mandarin and Arabic. His bachelor's degree in chemistry and a post-graduate diploma of education were obtained from two top-ranked universities in HK. These universities also use EMI. 


\section{Data Collection Procedures}

A semi-structured interview (e.g. Hammersley \& Atkinson, 2007) was conducted with the teacher in order to understand his perceptions of best practices and his attitudes towards using multiple languages in the EMI science and mathematics classrooms. The teacher was no longer teaching mixed EMI class in the academic year of 2019-2020. However, he uploaded a videorecording of his teaching of a year 8 science lesson in 2018 on Youtube in order to exhibit his pedagogical approaches to other science secondary teachers in HK. The video-recording was then used by me for research purposes. There were 30 students in the class and this class was classified as a mixed EMI class which involved both Chinese and SA students. The majority of the students in the class were SA who came from diverse ethnic and cultural backgrounds, including Pakistani, Nepalese, Indian and Filipino. Only seven students in the class were Chinese students. Despite being in an EMI science class, all the Chinese students in this class would take the Chinese version of the school examination. The SA students, on the other hand, would take the English version of the school science examination. All students were L2 English speakers and they have received at least 6 years of primary education. The Chinese students typically attended primary schools, where Cantonese was employed as the mediumof-instruction and English was taught as an L2. Four of the Chinese students were classified as overseas Chinese students as they spoke Mandarin as their L1s and they were born in the mainland China. Two Chinese students were identified as local Chinese students as they were born in HK and they spoke Cantonese as their L1s. SA students, on the other hand, typically attended primary school where English was used as the medium-of-instruction. Both the SA and Chinese students' English proficiency were deemed as satisfactory by the EMI teacher and it is acknowledged that the SA students generally have achieved a higher English proficiency than the Chinese students, based on the school's internal English examination. Many of the SA students in the class have grown up in HK or migrated to HK as a child and they could all understand or speak Cantonese.

I carried out classroom observation in the school for a month in June 2020. Schensul and LeCompte (2013: 88) define observation from a distance as 'the way researchers initially observe activities related to the topic of interest' in an unobtrusive manner. This study employs observation as a method to study the phenomenon (i.e. translanguaging practices) under investigation from a participant's perspective. During the fieldwork period, I observed a year 10 mathematics class, which is taught by the same EMI teacher. There were 40 students in the class and this class was an EMI class for SA students only. This class was chosen as the students were willing to give consent to me which allowed me to video-record their classroom learning processes for a month. As Heath and Hindmarsh (2002) point out, video-recordings 'allow us to capture version of conduct and interaction in everyday settings and subject them to repeated scrutiny using slow motion facilities and the like. Thus, they provide access to the fine details of conduct, both talk and bodily comportment' and 'to determine where people are looking and what they are looking at, and to recover the ways in which they orient to and handle objects and artefacts' (p. 103). During the classroom observation, one video camera was placed in the back of the classroom in order to capture the teacher's behaviour. The ethnic and cultural backgrounds of the SA students include Pakistani, Nepalese, Indian, Filipino, Yemeni and Russian. All SA students in the class were 16-year-old and they spoke English and Cantonese as their L2s. All students would take the English version of the school mathematics examination. 


\section{Combining Multimodal Conversation Analysis with Ethnographic Information}

The present study employs multimodal conversation analysis (MCA) and incorporates ethnographic information gained through interviews with the EMI science and mathematics teacher in order to examine the teacher's translanguaging practices in the classroom. MCA is used as the main analytical framework in the present study. The data were transcribed using Jefferson's (2004) and Mondada's (2018) transcription conventions (see Appendix). MCA 'focuses on how social order is co-constructed by the members of a social group' (Brouwer \& Wagner, 2004: 30) through finegrained analysis of the social interaction. It takes an emic/participant-relevant approach (Markee \& Kasper, 2004) in order to explicate the detailed process of how social actions, such as learning, are co-organised and achieved through talk-in-interaction. MCA allows researchers to analyse naturally occurring interaction and every minute detail 'is considered relevant in uncovering participant orientations toward the interaction' (Waring, 2008: 580). The analytic stance of MCA requires researchers not to pre-theorise the relevance and importance of language-in-use, which entails semiotic resources including eye gaze and gestures. The analytical focus must be on sequences instead of on isolated turns or utterances (Hutchby \& Wooffitt, 1998). This study first carries out the analysis in the conversation analytic framework and then ethnographic details are brought in whenever relevant in order to strengthen the MCA analysis and provide additional insights into the ways the teacher employed multilingual and multimodal resources to facilitate content teaching in his classrooms. Importantly, gaining ethnographic information, such as the participants' language attitudes, background, beliefs in teaching and learning and their own interpretations of the classroom interactions through interviews, is important in understanding how and why translanguaging is employed in specific moments of the classroom interactions, which is not accessible through a description of interactional sequence alone. Furthermore, since translanguaging practices entail multilinguals 'bring together different dimensions of their personal history, experience and environment, their attitude, beliefs and ideology, their cognitive and physical capacity' to facilitate their meaning-making processes (Li, 2011: 1223), MCA cannot reveal how participants bring various dimensions of personal history, ideologies beliefs etc. to create the translanguaging spaces in EMI science and mathematics classrooms (Li, 2011). These sociocultural factors may not emerge from the MCA analysis directly, but they can be explored through using interviews and/or an ethnographic approach. Hence, using ethnographic data gained through interviews potentially allows me to gather additional contextual information to inform the interpretations of my MCA analysis (Copland, 2011; Matsumoto, 2018; Waring \& Hruska, 2011).

\section{Selecting Representative Cases for Analysis}

For reporting purposes, I can only select the representative extracts instead of presenting all the transcribed interactional sequences. This may give rise to the issue of the representativeness of the analysed extracts in this study. To address this concern, the following aspects were considered:

- The presented extracts being directly or indirectly comparable to other extracts (ten Have, 1990);

- The deviant cases being considered (Ford, 2012).

As ten Have (1990) argues, regardless of a single-case (i.e. one particular extract) analysis or collections of instances (similar or different), MCA analysis 'is always comparative, either directly or indirectly' (ten Have, 1990: 34). In other words, the analysed extracts are inter-related to illustrate 
how the interactional features recurrently occurred (by relevantly similar instances) or how the features are employed in dissimilar ways (by deviant instances). In this study, the chosen extracts are typical instances of translanguaging practices in the EMI science and mathematics classrooms. Atypical sequences are not found in the study. It needs to be noted that the goal of MCA analysis is to find the 'devices', or 'the technology of conversation' in the speakers' situated interaction, instead of justifying the best possible representative extracts (ten Have, 1990). Therefore, as long as the selected extracts can address the research questions to reveal the relevant 'orderliness' with their representative nature, this can be said, to a large extent, that the representativeness is sufficient, or the research findings can be reliable.

\section{Analysis}

In the analysis, I will first present the MCA analysis of the mixed EMI science class and subsequently the MCA analysis of the EMI mathematics class for SA students only. It is worthy to note that although both classes were taught by the same teacher, there are confounding variables that could potentially shape T's translanguaging behaviour, including different syllabus (i.e. year 8 science and year 10 mathematics), different groups of students (i.e. year 8 students versus year 10 students) and potentially different Chinese and English language proficiency levels. Nevertheless, this study does not aim to quantify L1/L2 use nor seek to compare T's translanguaging behaviour between proficiency levels. I am interested in demonstrating translanguaging as a locally situated discursive practice which involves the orchestration of multiple multilingual and multimodal resources. Thus, including both types of classrooms from the HK EMI secondary school can allow the readers to explore different translanguaging behaviour in facilitating the meaning-making processes, overcoming the linguistic barriers and increasing inclusion and participation in the EMI classrooms.

\section{Mixed EMI Science Classroom}

In this section, two excerpts are extracted from the year 8 mixed EMI science lesson that was recorded in 2018 and the focus of the lesson is to introduce a new topic to students which is related to the basics of electricity and circuits. Extracts 1 and 2 are the representative cases that illustrate how the teacher creates a translanguaging space that is inclusive of linguistic differences.

\section{Extract 1}

Prior to the extract, the teacher $(\mathrm{T})$ introduced a new task which required students to identify the circuit symbol for each component. While the students were completing the task in groups, $\mathrm{T}$ projected the diagram of an actual circuit on the screen (image 1) which includes a translation of the English scientific term 'actual circuit' in standardised Chinese. In this extract, $T$ 's translanguaging practices involve the alternation of languages for input and output. This can be observed as $\mathrm{T}$ projects the actual circuit (prior to the extract) and places the circuit diagram next to the actual circuit via iPad in line 15. Both photos include the translations of the English scientific terms 'actual circuit' and 'circuit diagram' in standardised Chinese. Worth noting that standardised Chinese is a standard variety of Chinese. Cantonese is recognised as the de facto official spoken variety of Chinese in HK. At the same time, T verbally uses English to give instructions to students. $\mathrm{T}$ is making use of his English verbal utterances, the 
bilingual translations and the photos of the circuits which make the content accessible to all SA and Chinese students in the classroom. In lines 17-19, T first utters his question in English and then translates it into Cantonese in order to elicit responses from students. T's Cantonese translation eventually leads to students' uptake (line 21). This allows T to evaluate their understanding of the circuit symbol of a battery, as indicated by the positive assessment 'yes' in line 22.
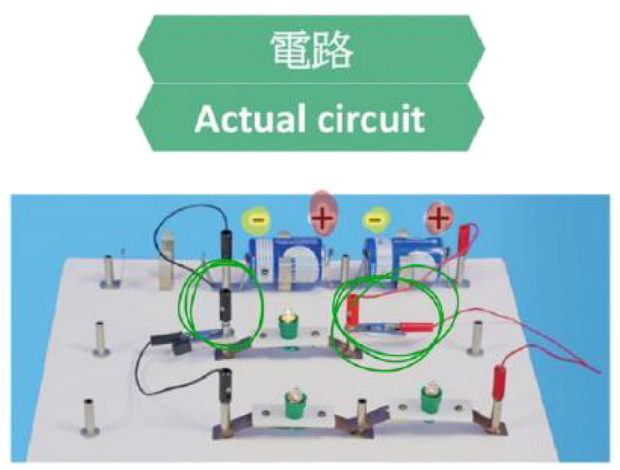

\section{Image 1}

$01 \mathrm{~T}$ : I want you to look at number three

$02(2.6)$

$03 \mathrm{~T}$ : now a battery has two poles (0.2) positive and?

$04(0.2)$

05 Ss: negative

$06(0.2)$

07 T: negative

$08(0.2)$

09 T: so how can 1 draw it accurately

$10(0.2)$

$11 \mathrm{~T}$ : that tell the person 1 am drawing the positive side

$12(0.2)$

$13 \mathrm{~T}$ : or the negative side

$14(0.5)$ 
$15 \mathrm{~T}$ : +now when you compare the drawing over there

+T looks down on his iPad

$+\mathrm{T}$ uses his fingers to touch the iPad screen

$+\mathrm{T}$ uses his iPad to drag two

diagrams on the same screen \#1

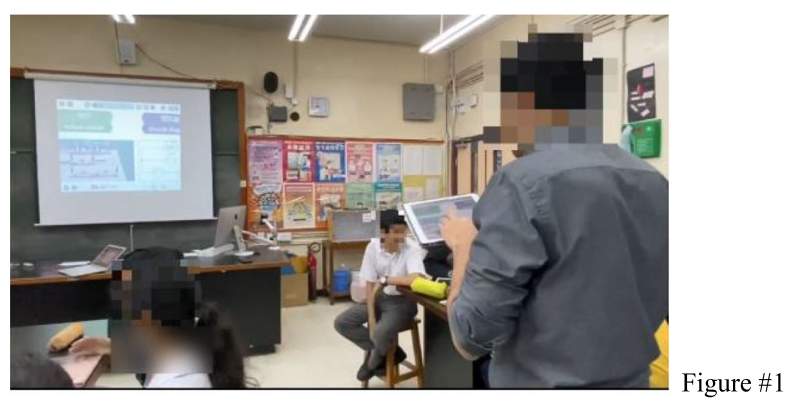

$16(0.6)$

$17 \mathrm{~T}$ : the longer one is positive or the shorter one

$18(0.2)$

$19 \mathrm{~T}$ ：長嗰邊係正呀 (0.2) 定係 (0.2) 短咱邊係正呀

((tr. the longer one is positive))

((tr. or $))$

((tr. the shorter one is positive))

$20(0.2)$

21 Ss: ${ }^{\circ}$ longer one ${ }^{\circ}=$

$22 \mathrm{~T}:=\underline{\text { yes }}$
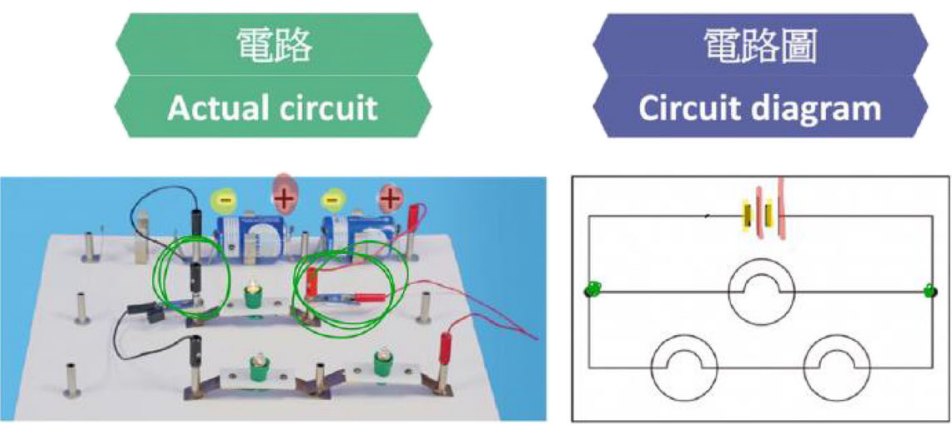

Image 2 
In lines 1 and $3, \mathrm{~T}$ asks the students to look at question three which requires students to draw the circuit symbol of a battery. In line 3 , $\mathrm{T}$ first introduces that ' $\mathrm{a}$ battery has two poles' and subsequently, he utters a designed-initiated utterance (DIU) by saying 'positive and?' (line 3). By doing so, T invites the students to complete the sentence for him. Several students respond to $\mathrm{T}$ by uttering 'negative' (line 5) which motivates $\mathrm{T}$ to repeat the answer in line 7 as a way to acknowledge their response. In lines 9-13, T continues to elicit responses from students by asking them how to draw the symbols to reflect the positive and negative sides of a battery. However, no student responds during the 0.5-s pause in line 14. T then uses his iPad to drag a circuit diagram and position it next to the photo of an actual circuit (image 2). Concurrently, $\mathrm{T}$ continues to use English to invite students to compare the photos: 'now when you compare the drawing over here' (line 15). As shown in image 1, translations of the English scientific terms in standardised Chinese (actual circuit and circuit diagram) are presented on top of the photos side by side. This illustrates that both SA and Chinese students, depending on their learning needs, can choose to look at either the English or standardised Chinese scientific terms when they are listening to T's English instruction. Such translanguaging practice (i.e. offering verbal instruction in English and written texts in both English and standardised Chinese) can assist them in recognising and identifying which circuit symbols match with the positive and negative sides of a battery.

After a pause, T attempts to elicit a response from the students, 'the longer one is positive or the shorter one' (line 17). This question allows students to determine which line (shorter or the longer one) represents the positive or negative side of a battery. After a short pause, $\mathrm{T}$ translates his English question into Cantonese (line 19), possibly encourages the Chinese students to respond to T's question. In line 21, some students utter 'longer one' softly which may indicate the uncertainty of their answer. In line $22, \mathrm{~T}$ instantly takes the turn and accepts the students' answer.

In this extract, $\mathrm{T}$ translanguages through making use of various linguistic resources (e.g. switching between Cantonese and English verbal utterances, providing standardised Chinese translations of the English scientific terms) and multimodal cues (including the use of diagrams and iPad) to give instructions to students and elicit student responses for assessing their scientific understanding. This interactional phenomenon can also be referred to as transduction (Kress, 2010) which refers to the shift of one semiotic mode to another semiotic mode. It is noticeable that $\mathrm{T}$ combines different modes (verbal utterances in Cantonese and English and the use of iPad) to construct a translanguaging space for enabling all students to grasp the scientific knowledge.

\section{Extract 2}

Extract 2 is the subsequent part of the interaction in Extract 1 (approximately 5 min after Extract 1). Prior to this extract, $\mathrm{T}$ was requesting students to complete an exercise on drawing the circuit diagram. T walked to different groups and took photos via his iPad to record the students' answers. T then uploaded a number of students' examples on the screen through the iPad and invited students to assess the appropriateness of the 
diagrams. In this extract, T's translanguaging practices can be observed through his switch between Cantonese and English and his use of verbal utterances alongside multimodal resources. T first initiates his question in English in line 6 and then translates it in Cantonese to make the question accessible to all students. $T$ then makes use of gestures and English to acknowledge the students' responses in English (line 10). From lines $12-24$, it is noticeable that $\mathrm{T}$ switches between Cantonese and English to initiate questions and evaluate students' responses. While $\mathrm{T}$ is speaking, $\mathrm{T}$ also makes use of the iPad to draw circles in order to help students to notice the mistakes of the circuit diagram. By doing so, T's translanguaging practices lead to several students' responses (e.g. lines 8 and 14) which reflects their appropriate understanding of using the correct circuit symbols to construct schematic diagrams.

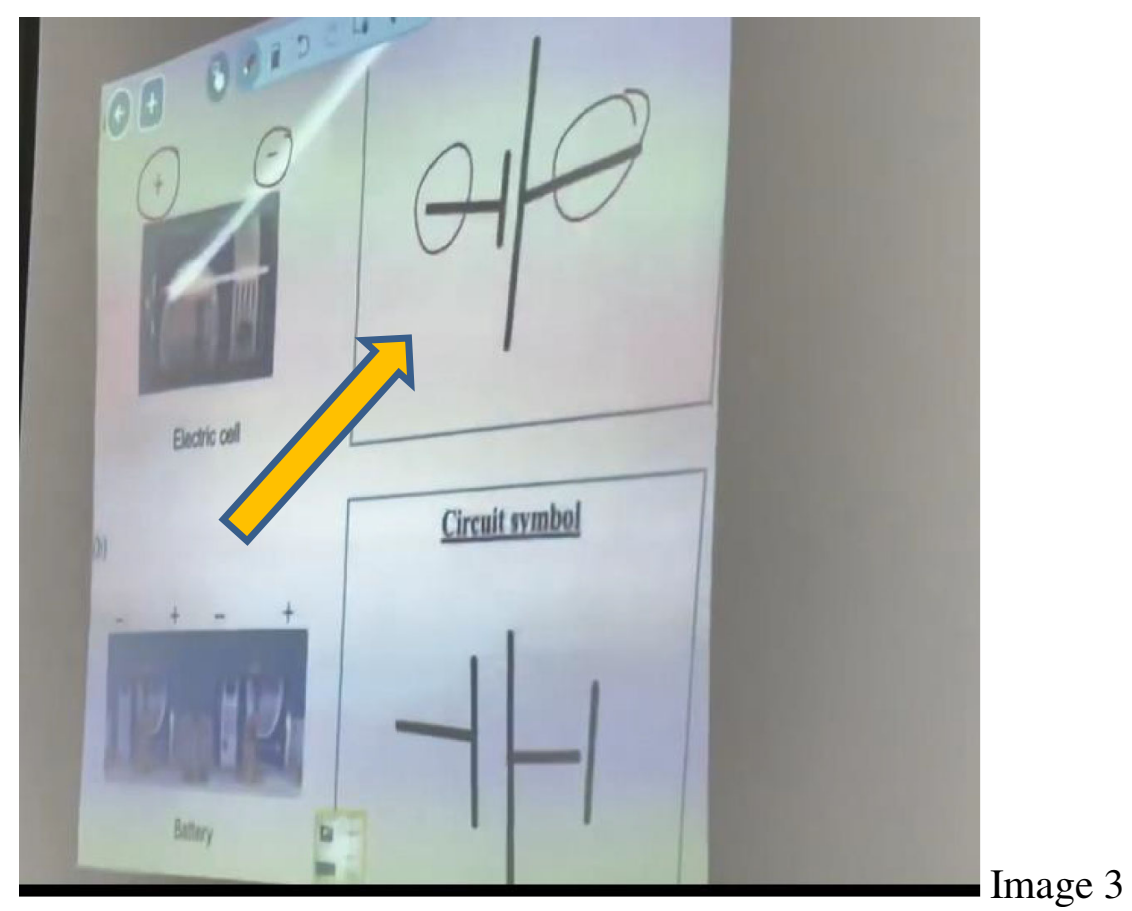


$01 \mathrm{~S} 1$ : the diagram is um shorter

$+\mathrm{S} 1$ points at the screen $\# 2$

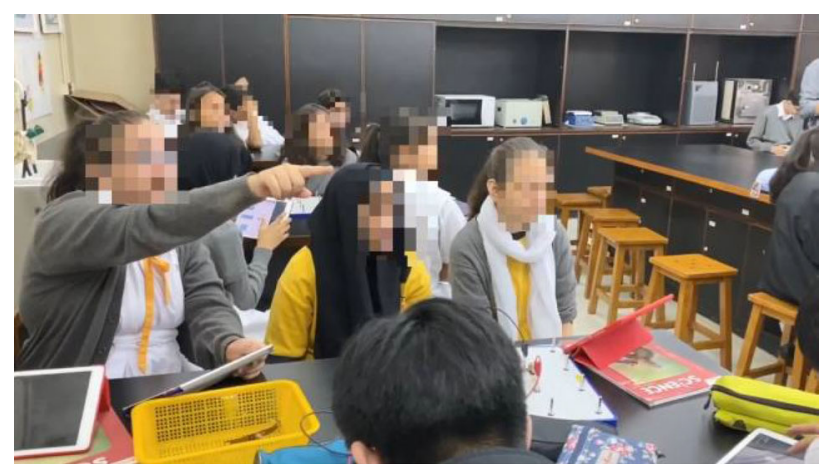

Figure \#2

$02(0.3)$

$03 \mathrm{~T}$ : yes very good (1.3) alright everyone=

$04 \mathrm{~T}:=+$ have a look at the screen please

$+\mathrm{T}$ points at the screen

$05+(1.5)$

$+\mathrm{T}$ turns to the students and extends his RH index finger

$06 \mathrm{~T}$ : which side is positive $(0.4)$ 邊一邊係正㕷

((tr. which side is positive))

$07 \quad(0.5)$

$08 \mathrm{Ss}$ : the left side

$09(0.3)$ 
$10 \mathrm{~T}:$ +the left side

+ $\mathrm{T}$ raises his $\mathrm{RH}$ to chest level, palm facing the screen

$+\mathrm{T}$ moves his RH arm to the LHS repeatedly \#3

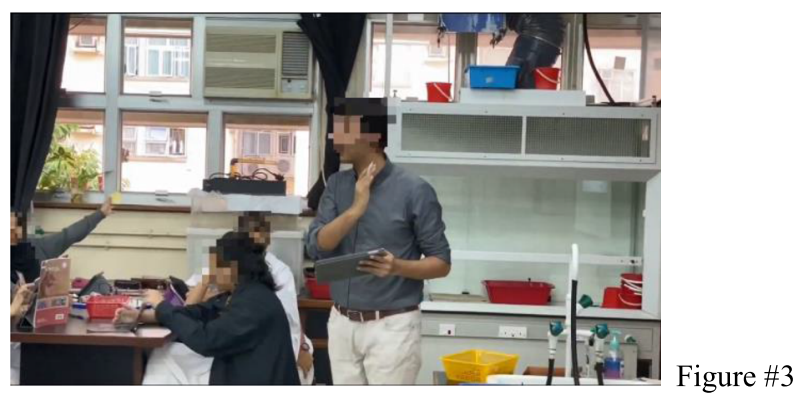

$11(0.4)$

$12 \mathrm{~T}$ ：+所以如果你記得噆話 (0.2) 正穊話係要長啲定係短啲啊

((tr. so if you can remember))

((tr. if it's positive, should it be alonger one or a shorter one))

$+\mathrm{T}$ moves his RH forward and upward, index finger and thumb are touching each other, other fingers curled \#4

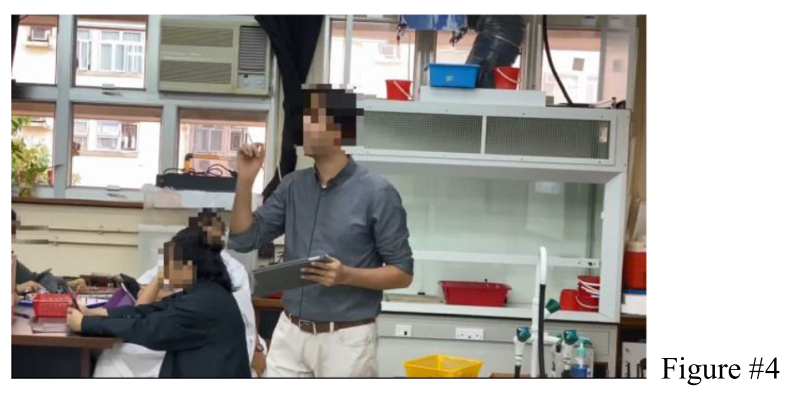

$13(0.4)$

14 S2: 長啲

((tr. longer $))$ 
$15(0.8)$

$16 \mathrm{~T}:$ +長啲 $(0.3)$ longer

((tr. longer $))$

$+\mathrm{T}$ extends all his fingers and moves his $\mathrm{RH}$ forward and upward \#5

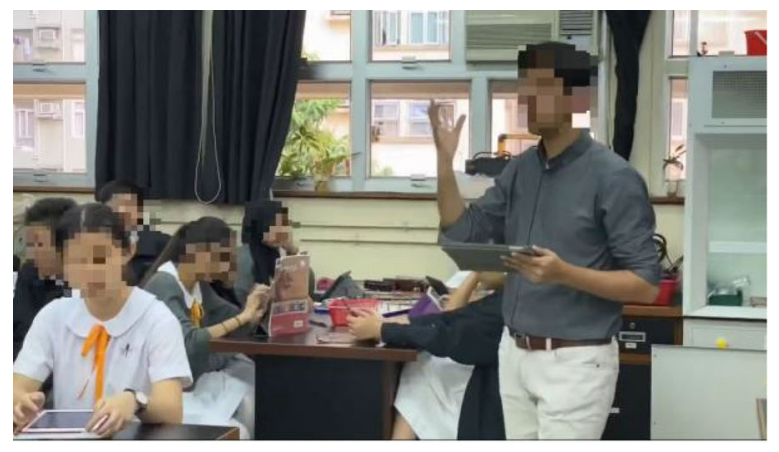

Figure \#5

$17(0.4)$

$18 \mathrm{~T}:$ +so if you draw like this (0.4) that is incorrect +T draws a circle around the short and long lines via his iPad \#6

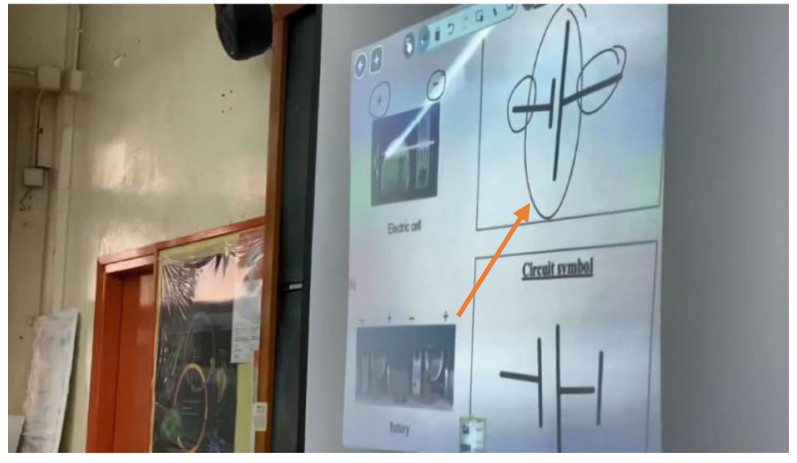

Figure \#6

$19(0.2)$

$20 \mathrm{~T}$ : that means you flip these two

21 (.) 
$22 \mathrm{~T}$ : 所以個正確答案呢應該係 (0.2) +長 (0.7) and then (10.0) +短 ((tr. so the correct answer should be)) ((tr. long)) ((tr. short))

+T draws a straight line via the iPad \#7 $+\mathrm{T}$ draws a shorter line on the iPad \#7

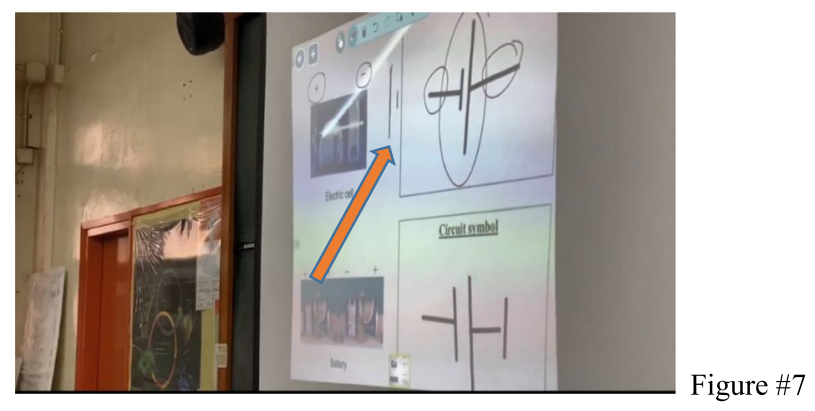

$23(0.6)$

$24 \mathrm{~T}$ : that's it (1.2) alright? (0.5) +long and then +short $+\mathrm{T}$ places his $\mathrm{RH}$ in front of him and moves his RH downward \#8

+ T holds RH above his head and extends his index finger and thumb with a small gap between them \#9 


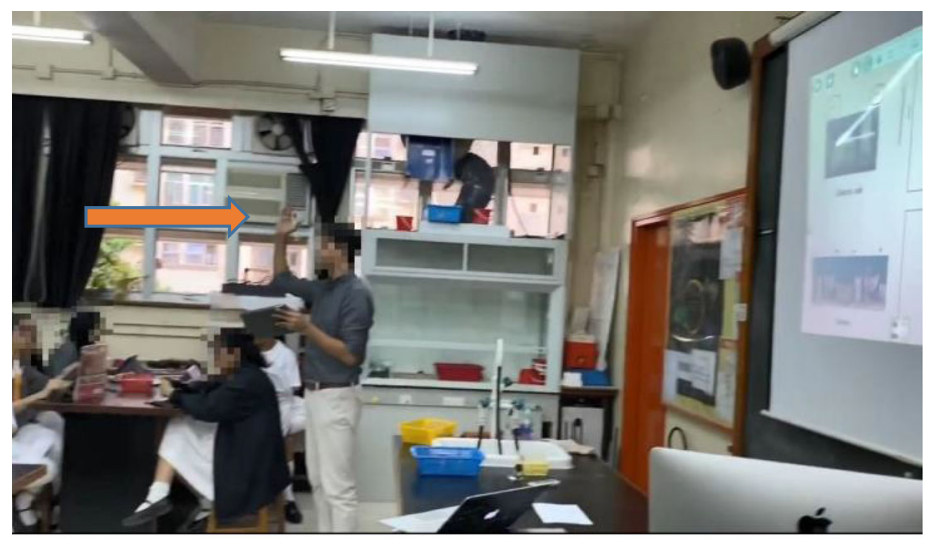

Figure \#8

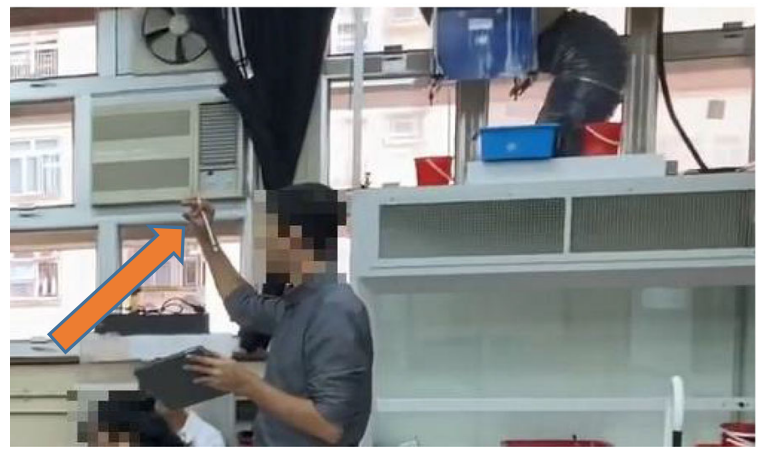

Figure \#9

$25(0.7)$

$26 \mathrm{~T}$ : +咁下面呢個呢

((tr. what about the one below $))$

$+\mathrm{T}$ looks at his iPad

$27(0.9)$

$28 \mathrm{~T}$ : how about this one

\section{$29(2.8)$}

In line $1, \mathrm{~S} 1$, who is a SA student, is invited to comment on a student's hand-drawn circuit symbol, 'the diagram is um shorter' (line 1). As we can see in image 3, the diagram suffers from a mistake where a shorter line is used to represent the positive side of a battery. Hence, S1 is pointing out the issue of using a shorter line. T confirms her answer in line 3 by uttering 'very good' and then asks students to pay attention to the screen (lines 3-4). In line 6, T asks 
students to point out which side of a battery (image 3 ) is positive. T translates the question in Cantonese after a 0.4-s pause (line 6) to ensure all students, including the Chinese students, understand his question. In line 8, several students reply 'the left side' and T acknowledges their answer in line 10 by echoing the answer and moving his arm to the left-hand side repeatedly in order to reiterate the fact that the positive side of a battery is located on the lefthand side.

$\mathrm{T}$ continues to initiate questions to guide students in understanding the mistake of the diagram. However, T deploys Cantonese to ask students to decide which line represents the positive side of a battery: “所以如果你記得嘅話 (0.2) 正嘅話係要長啲定係短啲啊 (so if you can remember (0.2) if it's positive, should it be a longer one or a shorter one)'. By initiating the question in Cantonese, $\mathrm{T}$ is possibly encouraging both SA and Chinese students to participate in the classroom interaction. This leads to a response from S2, a HK-based Chinese student, who enunciates '長啲 (longer)' and such response is confirmed by T in line 16. T first repeats S2's Cantonese response and translates it into English 'longer' in order to ensure both SA and Chinese students can comprehend the fact that the longer line represents the positive side of a battery. In line 18, T provides explicit feedback through switching back to English to point out the incorrectness of the diagram as well as drawing a circle around the short and long straight lines. $\mathrm{T}$ further comments that the student who drew this diagram should reverse the straight lines, 'that means you flip these two' (line 20), so that the long straight line comes before the shorter one. In line 22, T continues to provide feedback on the student's diagram by switching back to Cantonese and announces that an answer will soon be provided: “所以個正確答案呢應該 係 (so the correct answer should be)'. After a short pause, T utters '長 (long)' and concurrently draws a straight line next to the student's diagram which indicates that the longer line comes first. T subsequently switches to English momentarily as he utters 'and then' and switches back to Cantonese when he says '短 (short)' and simultaneously draws a shorter line next to the longer line in order to present a correct circuit symbol of a battery.

After offering explicit feedback through Cantonese and English utterances and drawings via his iPad, $\mathrm{T}$ then deploys gestural resources, alongside his English utterances, to visually illustrate length of the straight line to the students in line 24. After a 0.5 -s pause, $\mathrm{T}$ first utters 'long' and then moves his right-hand downward which symbolises the positive side of a battery. T then utters 'short' and extends his index finger and thumb with a small gap between them which represents the negative side of a battery. Since no student displays any nonunderstanding of T's explanation during the 0.7-s pause (line 25), T draws students' attention to the next question through using Cantonese and English in lines 26 and 28, respectively.

In Extract 2, it can be seen that T utilises various multilingual (Cantonese and English) and multimodal (e.g. use of iPad and gestures) resources to point out the differences between longer and shorter lines in representing the positive or negative side of a battery. The translanguaging practices here function as transduction which provides scaffolding that supports students' understanding of using the correct circuit symbols to construct schematic diagrams.

Based on the analysis of Extracts 1 and 2, it is revealed that T's translanguaging practices mostly involve the use of Cantonese and English, together with the use of multimodal resources including gestures and technology. It is vital to note that the teacher in this case is attempting to support both SA and Chinese students' understanding of the scientific concepts. In the semi-structured interview, the researcher invites $T$ to explain the pedagogical strategies that he has used in his year 8 mixed EMI science class: 


\section{Interview Extract 1}

T: um um um but in the lesson time 1 would not really like I can draw a line that aggregate them, it's more of, you know, sometimes I can ask a question in Cantonese, even the non-Chinese students can understand and they can reply in English, or they can reply in Cantonese as well.

\section{$\mathrm{K}$ : um hm}

T: You know, vice versa. I can ask a question in English, and Chinese student can answer in Chinese after understanding what I spoke in English. So, I would I would I do not prepare my lesson for that class in a way that all speaking English first and then I'll translate this in Chinese afterwards, I tend not to do this approach because it's kind of. It's very boring and even I get tired of it. So, what I like to do is I would mix like zigzag. So, I will try to use like for example, introducing a topic or, you know, explaining, I will first use simple terms to explain the concept in both English and Chinese or mix them both. When it when they understand the concept, then I will start adding those vocabulary, specifically in Chinese, and specifically in English.

\section{K: alright okay}

T: So, this way you know Chinese students who are aware of this. Oh okay, I have to memorize this one or that English students will be like oh okay 1 have to memorize this one.

T comments that he cannot always translate his scientific explanations into a student's preferred language. This is possibly because students in the class do not share a common L1 with the teacher and other classmates. He notices that the SA students in his class do understand Cantonese and the Chinese students are not completely unable to understand English. This motivates him to adopt an open-minded attitude by allowing students to respond to his questions in either Cantonese or English. Such attitude is reflected in the MCA analysis of Extracts 1 and 2 where T draws on both Cantonese and English, accompanied by the use of various multimodal resources, to scaffold students' understanding of the scientific content. In this way, $\mathrm{T}$ is not setting any rules for students in their language choice and he encourages students to purposely choose linguistic resources that they feel comfortable with. T deploys the metaphor of 'zigzag' to emphasise his attitude of using any language flexibly in order to create an inclusive classroom culture and cater to different students' linguistic needs. Such a flexible approach is particularly necessary when the two groups of students (SA and Chinese students) are either taking the Chinese or English version of the school examination. This can assist students in the mixed EMI class to attain scientific knowledge, familiarise students with the ways of scientific thinking through deploying the discursive practices of science and promote 
meaningful learning in the classroom which is intellectually challenging at their level. In the below interview extract, T continues to explain how using Cantonese and English can allow him to carry out his teaching successfully in the classroom.

\section{Interview Extract 2}

T: So, this way you know it makes the lesson more alive and interactive than two versions and plus I have only one hour, and so, I cannot like you know half half lesson use English half lesson use Chinese. That would be very, very boring.

$\mathrm{K}$ : yeah

T: So that, that's, that's one way. I mean, it was a struggle very beginning. Because just last year I started teaching a a class I was very nervous. I mean, I've not taught a subject in Chinese, especially if it comes to science.

K: yeah

T: But um I mean, thanks to the students last year. I mean, I got to learn that you know that Chinese students are not really completely unable to understand English and vice versa, you know, the English students can understand Chinese, to a certain extent, so why not ask questions in one language that both can understand so they can reply with whatever language that they would love to. So just like I I just experienced I collected last year. Useful to me for just continually change the classroom dynamics.

$\mathrm{T}$ acknowledges that switching between Cantonese and English can allow $\mathrm{T}$ to create a classroom environment which potentially encourages students' participation in the classroom. $\mathrm{T}$ also acknowledges that time constraint is a factor which does not allow him to deliver the lesson in 'half English' and 'half Cantonese'. T then recalls his experience as he taught this mixed class in 2018. He recognises that he is not experienced in using Cantonese to teach content subject. As previously noted, he has achieved a native-like English proficiency and he is more confident in conversing in English. It can be argued that $\mathrm{T}$ is required to draw on his limited linguistic knowledge of Cantonese to teach science which entails abstract scientific language. After T's realisation that the Chinese students could understand his English instruction and the SA students, to some extent, could also understand T's Cantonese, this encourages $\mathrm{T}$ to use the common languages (Cantonese and English) in the classroom. Although $\mathrm{T}$ can speak Urdu and Punjabi, he did not use these languages in the classroom in which the majority of the students come from SA. It is possible that the class consists of SA students, who share different L1s and cultural backgrounds, and local and overseas Chinese students who speak Cantonese or Mandarin as their L1. In order to ensure all students can understand the scientific content, this can explain why $\mathrm{T}$ chooses to deploy English and Cantonese in the classroom since these are the languages that are familiar to all students. By doing so, T's translanguaging practice facilitates the creation of a culture of school science that promotes inclusion and 
makes links between the students' familiar language and scientific language, which supports students' understanding of scientific concepts.

\section{EMI Mathematics Class for SA Students}

Extract 3 is extracted from the year 10 EMI mathematics lesson which was taught by the same teacher in June 2020. Extract 3 is a typical example that illustrates how the teacher draws on English as a common language and other multimodal resources to facilitate students' understanding of the mathematical question.

\section{Extract 3}

Prior to the extract, T projects the mathematical equation on the screen via his iPad and invites students to discover ways to solve the equation (image 4). Several students realised that they needed to combine two variables into one variable, but the other students had no idea how to solve it. In line 51, T decides to give an example so that all students can understand how they can solve the equation. In this extract, T's translanguaging practices can be observed through his use of iPad for writing down the mathematical formula, in conjunction with his verbal instruction in English (e.g. lines 53-57, 80 and 84), using metaphoric gestures with speech to facilitate the mathematical explanation (e.g. lines 57, 80 and 82), using both verbal speech and different colours of highlight pens, a function that is afforded by $\mathrm{iPad}$, to help students to notice the salient mathematical variables, such as $\mathrm{a}^{2}$, in lines 80 and 91 .

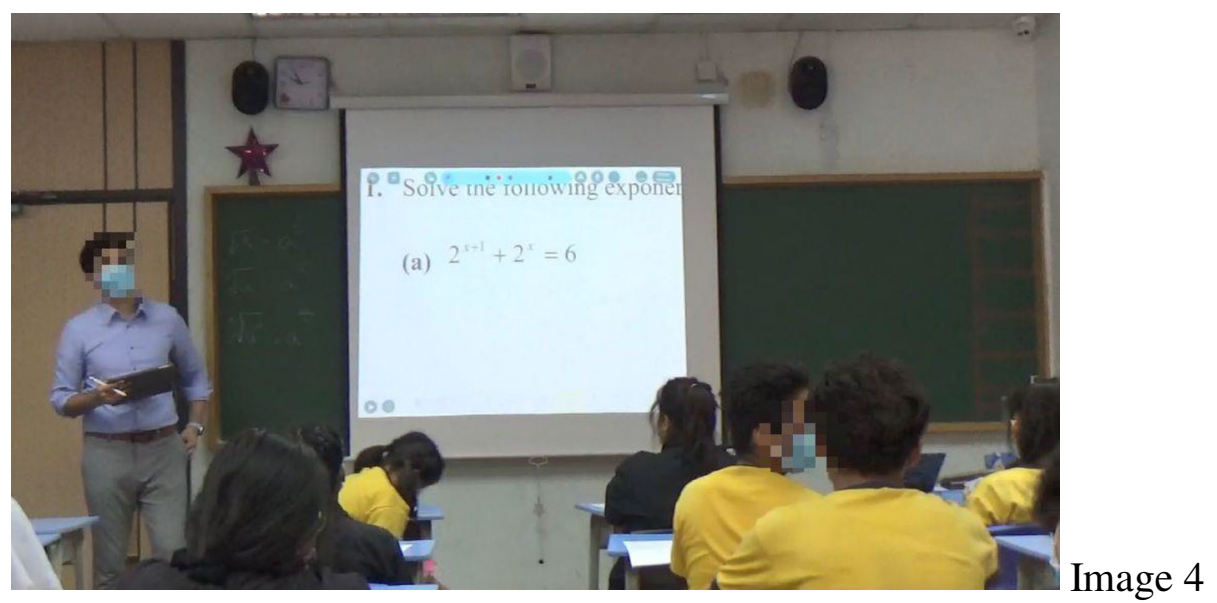


$51 \mathrm{~T}$ : +okay 1 will +give you a hint (1.5) +alright?

$+\mathrm{T}$ looks at students

$+\mathrm{T}$ picks up his iPad

$52(0.4)$

$53 \mathrm{~T}$ : um $+(10.2)$ if 1 have to solve a

$+\mathrm{T}$ writes down an equation via iPad \#10

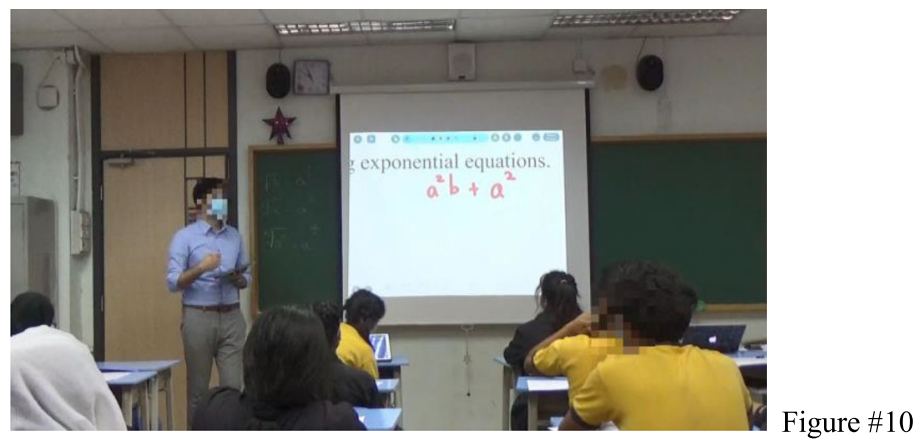

$54(0.4)$

$55 \mathrm{~T}$ : now they are two separate As

$56+(1.4)$

$+\mathrm{T}$ writes "=1"

$57 \mathrm{~T}$ : what do 1 have to do next (2.1) +can 1 combine them?

$+\mathrm{T}$ curls his thumb and index finger to form a c-shaped gesture and closes the gap between fingers

$58(0.2)$

59 SS: ya:=

60 SS: $=$ no=

$61 \mathrm{~T}$ : =why not

$62(1.1)$ 


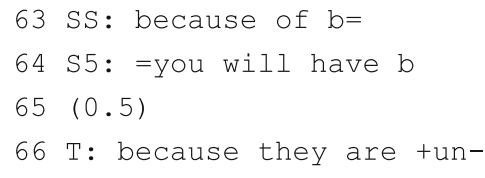

$+\mathrm{T}$ extends his right arm, palm facing upward

$67(0.3)$

68 S5: known

$69(0.3)$

$70 \mathrm{~T}$ : +un- what unlike terms

$+\mathrm{T}$ moves his RH in circular motion

$71(0.3)$

$72 \mathrm{~T}$ : alright they are not like terms=

$+\mathrm{T}$ moves his RH backward and forward repeatedly

$73 \mathrm{~T}$ : = so we cannot combine them so is there anyway=

$74 \mathrm{~T}$ : =to combine the two a square?

$75(0.6)$

76 S5: take out the b

$77(0.2)$

78 S2: take out the common factor

$79(0.3)$

$80 \mathrm{~T}$ : +very good (0.7) +instead of +focusing on tadding them $+\mathrm{T}$ points at $\mathrm{S} 2$

+ T highlights the common term ' $\mathrm{a}^{2}$ ' with yellow highlighter via iPad

$+\mathrm{T}$ curls his thumb and index finger to form a c-shaped gesture

$+\mathrm{T}$ closes the gap between thumb and index finger \#11

$+\mathrm{T}$ highlights the another common term ' $\mathrm{a}^{2}$, with yellow highlighter 


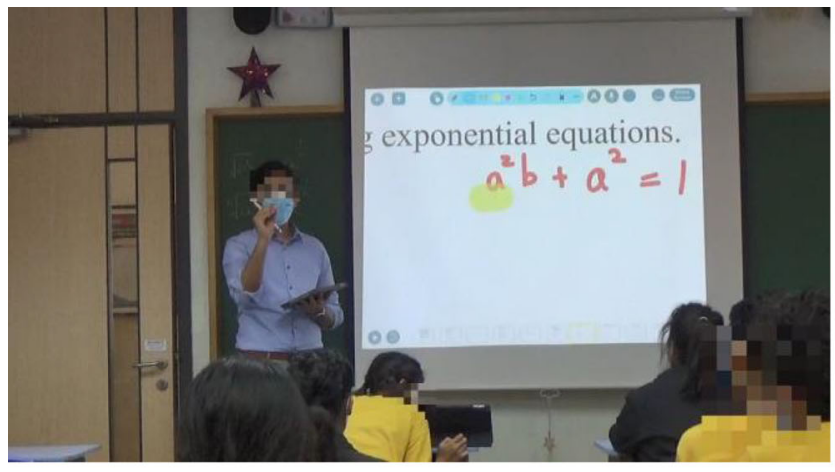

Figure \#11

$81(0.6)$

$82 \mathrm{~T}$ : we +focusing on thaking out the common factor $+\mathrm{T}$ stretches out his right arm, palm facing downward \#12

$+\mathrm{T}$ moves his right arm towards his face \#13

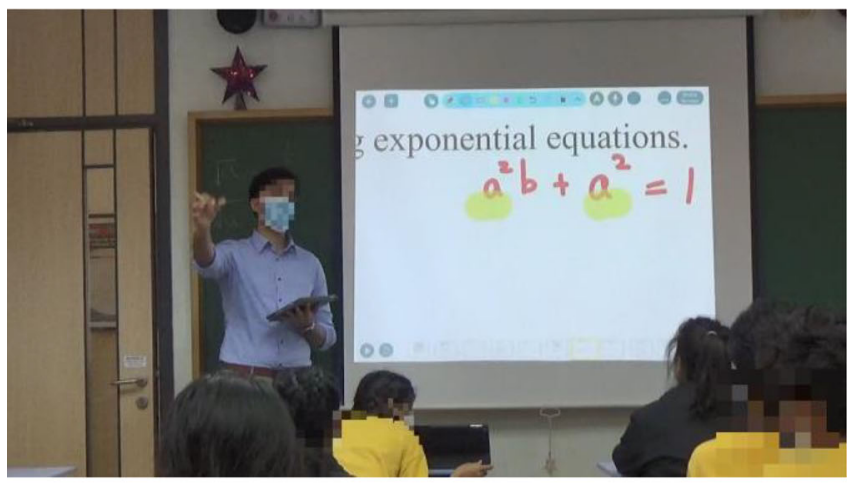

Figure \#12

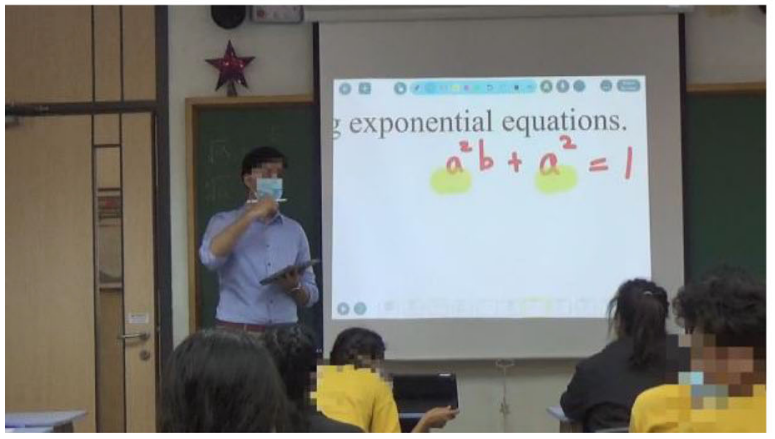

Figure \#13

$83(0.3)$

$84 \mathrm{~T}$ : +so in this case this will become a square= $+\mathrm{T}$ writes down $\mathrm{a}^{2}$ ( ) via iPad, with an empty bracket \#14 


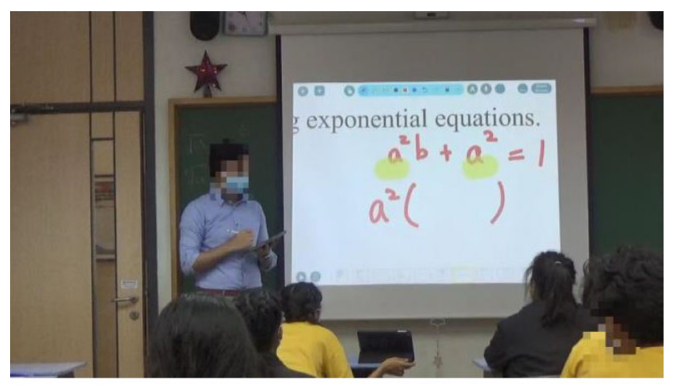

Figure \#14

$85 \mathrm{~T}:$ = what is that behind?

$86(0.4)$

87 SS: b

$88(0.3)$

89 S2: b plus one

$90+(0.7)$

$+\mathrm{T}$ writes down the new equation via iPad \#15

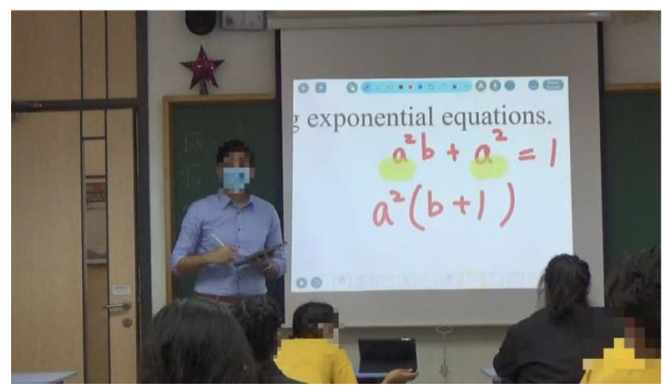

Figure \#15

$91 \mathrm{~T}$ : and then you will notice that we are able to +convert=

$+\mathrm{T}$ highlights ' $\mathrm{a}^{2}$ ' in green colour via

iPad \#16 


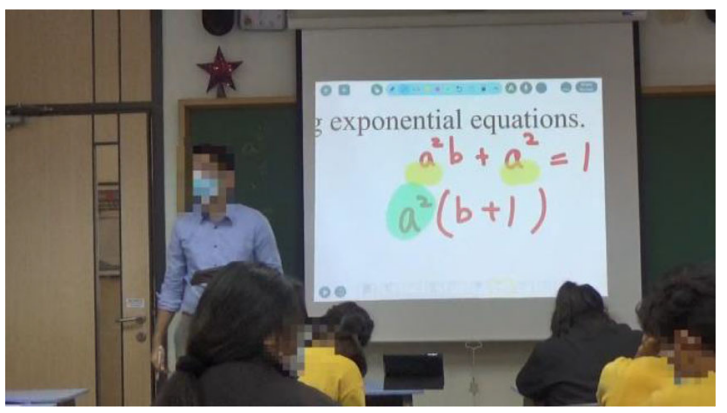

Figure \#16

$92 \mathrm{~T}:$ =into one a square okay?

$93(1.2)$

$94 \mathrm{~T}$ : +now keep this in mind because=

$+\mathrm{T}$ curls his thumb and index finger to form a c-shaped gesture

$95 \mathrm{~T}$ : =we will use similar technique over there

$+\mathrm{T}$ zooms into the new question

In line 51, $\mathrm{T}$ uses his iPad and zooms into a blank page which signals to the class that $\mathrm{T}$ is going to provide hints on the page. He then writes down an equation ' $\mathrm{a}^{2} \mathrm{~b}+\mathrm{a}^{2}$ ' via his iPad (line 53) and describes the nature of this equation, 'now there are two separate As' (line 55). T then curls his thumb and index fingers to form a c-shaped gesture and closes the gap between fingers while asking students whether it is possible to 'combine' the two variables in order to solve ' $a$ '. Momentarily, his thumb and index fingers represent the two mathematical variables ' $\mathrm{a}^{2} \mathrm{~b}$ ' and ' $\mathrm{a}^{2}$ ', respectively. This leads to several students' responses in lines 59 and 60 . T asks students to explain why it is not acceptable to combine them together (line 61). Although several students attempt to come up with the right answer, such as 'because of b' in line 63 and 'you will have b' in line 64, these responses are not considered as acceptable. This leads to T's follow-up response as he gives a hint to students, 'because they are un-' (line 66). Note that T's utterance is a DIU since $\mathrm{T}$ does not immediately provide a response to the students and $\mathrm{T}$ is inviting them to complete the utterance for T. Since S5 provides the wrong answer (line 68), T then makes it clear that the two variables are 'unlike terms' and therefore they cannot be combined (lines 70-73).

$\mathrm{T}$ then moves on and asks whether there is any way to combine the $\mathrm{a}^{2}$ in the equation (lines 73-74). This leads to several responses from S5 and S2. S5 suggests T to take out the ' $b$ ' in the equation and S2 argues for taking out the common factor ' $a$ '. Both answers are deemed as appropriate by $\mathrm{T}$, indicated by his positive assessment 'very good' in line 80. After a 0.7 -s pause, T further elaborates S5 and S2s' responses to other students so that other students will understand the logic behind it. $\mathrm{T}$ first explains 'instead of focusing on adding them' and concurrently enacts the metaphoric gesture (see McNeill, 1992) of 'combining' by curling his thumb and index finger to form a c-shaped gesture and then closing the gap between them. $\mathrm{T}$ also highlights the two variables ' $\mathrm{a}^{2}$ ' with the yellow highlighter via iPad to assist students in noticing them (line 80). $\mathrm{T}$ then continues and explains that 'we focusing on taking out the common factor'. When T utters 'take', T synchronises his speech with his action of moving his 
right arm towards his face, which enacts the movement of taking something (line 82). Here, T's use of metaphoric gestures in lines 80 and 82 reiterates the fact that students need to take out the common factor from the equation rather than combining them. In line 84 , $\mathrm{T}$ writes down a new equation which reflects the removal of the variable, $\mathrm{a}^{2}$, and simultaneously, he verbally states that 'this will become a square'. Notes that $\mathrm{T}$ has left the bracket empty and $\mathrm{T}$ invites students to fill in the gap for him, 'what is that behind?' (line 85). Several students offer incomplete responses in line 87. S2 takes the turn and utters 'b plus one' in line 89 which results in T's non-verbal acknowledgement. Such an acknowledgement is shown in line 90 when $\mathrm{T}$ writes down ' $\mathrm{b}+1$ ' on the screen to complete the equation. In lines 91-92, $\mathrm{T}$ initiates another sequence and he invites students to note that they can now convert the original equation ' $\mathrm{a}^{2} \mathrm{~b}+\mathrm{a}^{2}$ ' which involves two ' $\mathrm{a}^{2}$ ' into one ' $\mathrm{a}^{2}$ ' in the new equation, ' $\mathrm{a}^{2}(\mathrm{~b}+1)$ '. In particular, T switches the yellow highlighter to green highlighter and highlights ' $\mathrm{a}^{2}$ ', which is a variable in the new equation, in order to indicate ' $\mathrm{a}^{2}$ ' as the common variable. After that, $\mathrm{T}$ explicitly asks students to remember the steps that $\mathrm{T}$ has gone through with students as they 'will use similar technique' (line 95) to address the question that students fail to solve prior to the extract.

Throughout Extract 3, T is orienting towards the English-only norm in the EMI classroom and no other named languages, such as Cantonese, are used. This is also reflected in the semistructured interview when $\mathrm{T}$ is asked to comment about his use of language in his year $10 \mathrm{EMI}$ mathematics class with SA students only:

\section{Interview Extract 3}

\section{$\mathrm{K}$ : But um what about in your classrooms like your full mathematics EMI class?}

T: oh, English definitely English. Um unless I have Chinese students then 1 would obviously say Chinese um Cantonese. But um like my science class, Cantonese or English they can ask in both, talking both but if it's only um all non-Chinese students they can speak in English but there are some non-Chinese students whose Chinese is way way way better than their English because they studied in um proper like a full Chinese like um a CMI school yes. In primary. So, they feel comfortable in asking questions in Cantonese. So that's also fine.

T explains that he will 'definitely' use English in the full EMI class since there are no Chinese students in the class and he does not feel the need to use other languages other than English to carry out his teaching. He compares it with his former mixed EMI science class where he needs to draw on both Cantonese and English so that both groups of students (SA and Chinese students) can fully participate in the science lessons. Although Extract 3 does not illustrate how $\mathrm{T}$ makes use of multilingual resources to scaffold students' learning when teaching full EMI class, it is argued that $\mathrm{T}$ has skilfully deployed transduction as a translanguaging practice which allows him to mobilise multimodal resources to scaffold his use of English in the classroom. This extract has shown that T's translanguaging practices involve the use of various multimodal resources (e.g. use of iPad writing, switch of different colours of highlight pens and use of metaphoric gestures) which synchronises with T's English utterance. Notably, T's use of English involves mathematical discourse that is different from 
everyday language. Such translanguaging behaviour affords opportunities for T to convey the most relevant mathematical steps in a clear manner to his students.

\section{Discussion and Conclusion}

\section{Summary of the Research Findings}

Contemporary scholarship has illustrated that translanguaging challenges the monolingual pedagogical principle adopted in traditional EMI classrooms since it poses a serious challenge to equity (Lin \& He, 2017). This article has adopted translanguaging as an analytical perspective in order to reveal how the EMI science and mathematics teacher mobilises various multilingual and multimodal resources to promote meaning-making and knowledge construction, creates a culture of school science and mathematics for students to be inducted into the discursive and semiotic practices of the discipline, and promotes inclusion and participation in EMI classrooms for linguistically and culturally diverse students. Extracts 1 and 2 analyse examples of how the teacher teaches a year 8 mixed EMI science class with SA and Chinese students. Extract 1 demonstrates how the teacher utilises photos (an actual circuit and a circuit diagram), technological aid (iPad), different varieties of Chinese (i.e. translations of English scientific terms in standardised Chinese and translations of his English questions in Cantonese) and switching between spoken English and Cantonese to guide students in drawing the correct circuit symbol of a battery. Similarly, Extract 2 illustrates how multilingual and multimodal (e.g. use of gestures, drawings and visuals) resources are used to assist students in realising the mistakes in the student-produced circuit symbol of a battery. Such translanguaging practices are similar to the findings that are documented in the HK EMI literature where the EMI science teachers draw on various multilingual and multimodal resources to scaffold students' learning (e.g. Lin \& Wu, 2015; Wu \& Lin, 2019) and promote a humorous classroom context (Tai and Li Wei, 2021a). Extract 3 analyses a representative extract of a classroom interaction where the EMI teacher teaches a year 10 EMI mathematics class which only involves SA students. Extract 3 reveals that $\mathrm{T}$ is engaging in translanguaging practices despite only using English as the linguistic code. It is shown that $\mathrm{T}$ is also engaging in translanguaging practices as he synchronises his English verbal utterances with his use of metaphor gestures and his use of technological resources (i.e. iPad) which affords opportunities for him to write down mathematical formulas and use different colours of highlight pens to indicate key mathematical variables. In all extracts, the MCA analysis shows that T's use of translanguaging practices has assisted students in grasping the scientific and mathematical concepts, which is evidenced in students' appropriate and accurate responses to T's guided questions.

\section{Theoretical and Methodological Implications}

This study reinforces the view of inclusive pedagogy as a right to participate in educational practices and explain how EMI science and mathematics teachers can potentially draw on translanguaging practices to construct cultures of school science and mathematics that can include students in the process of content learning and encourage students to participate in collaborative talk and co-construction of understandings. As the importance of translanguaging is recognised in the field of multilingualism and scholars have been recommending EMI teachers to incorporate translanguaging more regularly in the EMI classrooms (e.g. Li, 2018; 
Lin, 2019), it becomes necessary to extend the view by conceptualising the orchestration of resources for enacting inclusive practices. The notion of translanguaging conceives with the ideas of promoting equity and social justice in the classrooms. It concerns the entirely of the teacher's and students' repertoire (Garcia \& Li, 2014; Woodley, 2016). I propose that the enactment of inclusive practices involves a process of translanguaging whereby the teachers need to seek out available multilingual and multimodal resources and make strategic choices among these resources in order to bring inclusive teaching practices into the EMI classrooms. Through engaging in translanguaging, it can allow teachers to help students to transcend from their everyday life culture into the cultures of science and mathematics (Aikenhead 1996; Cobern \& Aikenhead, 1998; Jegede \& Aikenhead, 1999). Such a process of translanguaging also involves teachers adopt pluralistic attitudes in order to embrace resources that are available in the classroom to make the discipline-specific knowledge accessible to all students and honour the students' diverse multilingual and multicultural backgrounds and communicative resources (Tai and Li Wei, 2020, 2021a, 2021b, 2021c). In the interview with the EMI teacher, it is evidenced that the teacher exhibits an open attitude towards the flexible use of language in the EMI science and mathematics classrooms. Such an attitude is reflected in the MCA analysis (Extracts 1, 2 and 3) where the teacher engages in a variety of multilingual and multimodal sign-making practices in the process of teaching to ensure students all students understand the content knowledge and encourage them to participate in the classroom interaction. This demonstrates that the teacher's open-minded attitude has carved out a translanguaging space $(\mathrm{Li}, 2018)$ and cultures of school science and mathematics at a whole-class level (Trussler \& Robinson, 2015) where he allows students to express their meanings (by drawing on their familiar linguistics resources), offers drawings and photos on the screen and uses accompanying gestures to assist his students to access the content knowledge and academic discourse (e.g. scientific and mathematical terminologies).

Adopting translanguaging as an analytical perspective on studying inclusive pedagogy helps us to shift our attention from using different linguistic codes for promoting inclusion to the way that teachers can create diverse multilingual, multimodal and multisensory signmaking practices for making learning accessible for all in a multilingual EMI classroom. To date, there is very little literature on inclusive practices in science and mathematics education (Piliouras \& Evangelou, 2012; Roos, 2019) and there is still limited research conducting finegrained analysis to study the role of translanguaging in enacting inclusive practices in EMI classroom interactions. Moreover, linguists traditionally focus on conventionalised speech and writing and pay little attention to other semiotic cues that construct the meanings in real-life social interaction (Kress, 2004; Li, 2020). Particularly, a considerable amount of research on translanguaging in EMI classroom interaction (e.g. Doiz \& Lasagabaster, 2017; Sahan \& Rose, 2021), as well as studies which examine inclusive practices in multilingual classrooms (e.g. Woodley, 2016), only conceptualise translanguaging as practices that indicate the movement among linguistic repertoires. The translanguaging perspective emphasises the significance of transcending boundaries between linguistic and other multimodal means which creates opportunities for EMI teachers to convey aspects of the relevant discipline-specific knowledge for their students. The findings of this study provide illustrative examples of an EMI science and mathematics teacher's ability to switch or combine a range of resources available to him flexibly that affords him to create a more inclusive multilingual and multimodal classroom environment for furthering science and mathematics teaching and students' learning. Methodologically, this study highlights how adopting translanguaging as an analytical perspective can 
help us in understanding inclusive pedagogical practice as a dynamical process of addressing and responding to diverse learning needs.

\section{MCA transcription conventions (adapted from Jefferson, 2004 and Mondada, 2018)}

\section{Sequential and timing elements of the interaction}

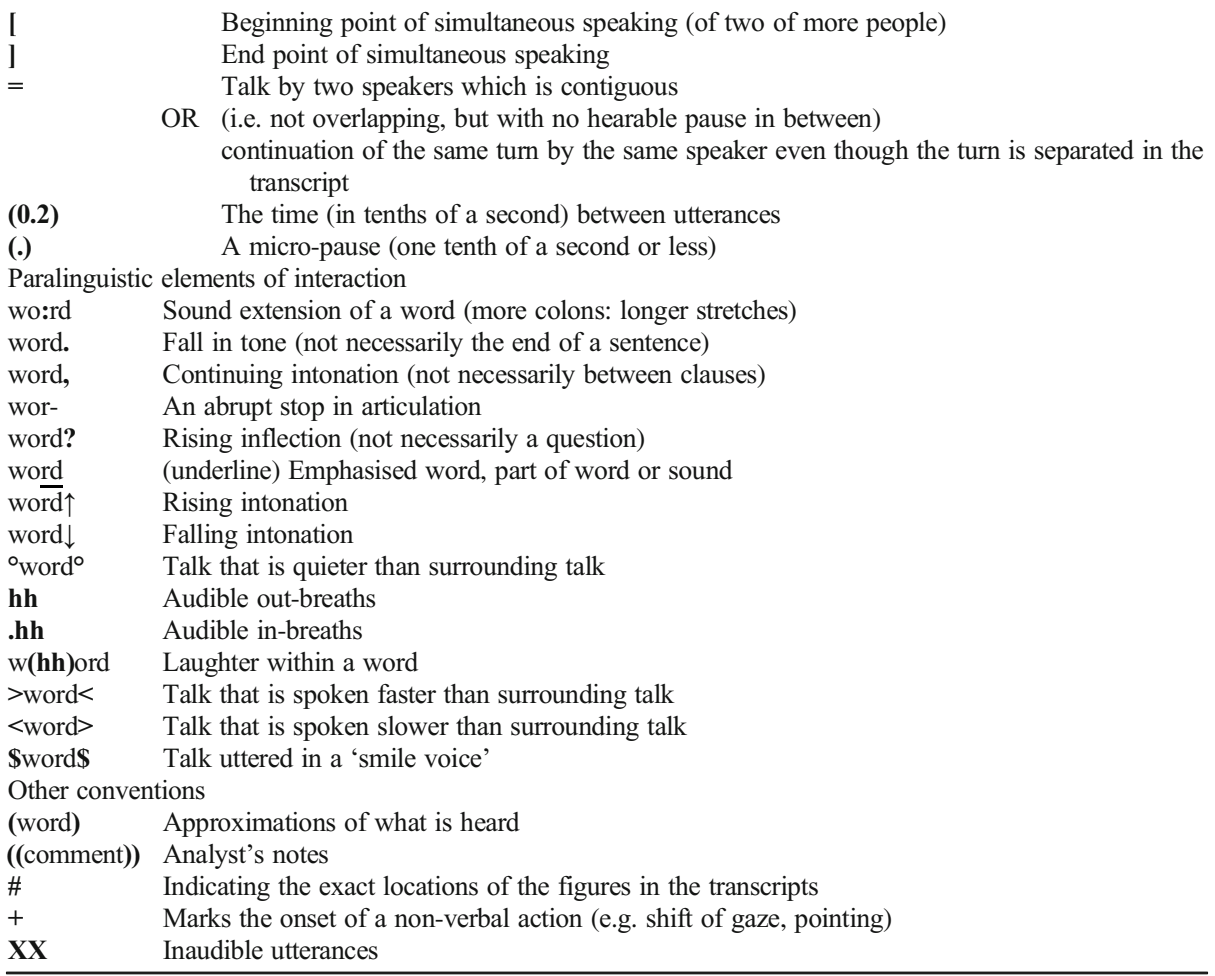

Acknowledgements First and foremost, I would like to thank the EMI science and mathematics teacher who participated in this study. I would like to thank Professor Li Wei, Mr. Samuel Tsang and Mr. Ivan Liu for giving me invaluable ideas and input for this paper. Thanks must also be given to the anonymous reviewers who took time to give feedback on my work.

Funding The work described in this paper was supported by the UK Economic and Social Research Council (Grant Reference: ES/P000592/1).

Open Access This article is licensed under a Creative Commons Attribution 4.0 International License, which permits use, sharing, adaptation, distribution and reproduction in any medium or format, as long as you give appropriate credit to the original author(s) and the source, provide a link to the Creative Commons licence, and indicate if changes were made. The images or other third party material in this article are included in the article's Creative Commons licence, unless indicated otherwise in a credit line to the material. If material is not included in the article's Creative Commons licence and your intended use is not permitted by statutory regulation or exceeds the permitted use, you will need to obtain permission directly from the copyright holder. To view a copy of this licence, visit http://creativecommons.org/licenses/by/4.0/. 


\section{References}

Aikenhead, G. S. (2001). Students' ease in crossing cultural borders into school science. Science \& Education, $85,180-188$.

Ainscow, M., Booth, T., \& Dyson, A. (2006). Improving schools, developing inclusion. Routledge.

Arnow, J. (2001). The school in a multicultural society: Teaching tolerance and conflict resolution. In M. Shafii \& S. L. Shafii (Eds.), School violence: Assessment, management, prevention (pp. 291-302). American Psychiatric Association.

Averill, R. (2012). Caring teaching practices in multiethnic mathematics classrooms: Attending to health and well-being. Mathematics Education Research Journal, 24(2), 105-128.

Brouwer, C. E., \& Wagner, J. (2004). Developmental issues in second language conversation. Journal of Applied Linguistics, 1(1), 29-47.

Cobern, W. W., \& Aikenhead, G. S. (1998). Cultural aspects of learning science. In B. J. Fraser \& K. G. Tobin (Eds.), International handbook of science education (pp. 39-52). Kluwer Academic Publishers.

Connelly, J., Gube, J., \& Thapa, C. B. (2013). Hong Kong's ethnic and linguistic minority immigrant students: An evaluation of educational support measures. In E. L. Brown \& A. Krasteva (Eds.), Migrants and refugees: Equitable education for displaced populations (pp. 191-214). Information Age Publishing.

Copland, F. (2011). Negotiating face in feedback conferences: A linguistic ethnographic analysis. Journal of Pragmatics, 43, 3832-3843.

Doiz, A., \& Lasagabaster, D. (2017). Teachers' beliefs about translanguaging practices. In C. Mazak \& K. Carroll (Eds.), Translanguaging in higher education: Beyond monolingual ideologies (pp. 157-176). Multilingual Matters.

Education Bureau. (2009). Fine-tuning the medium of instruction for secondary schools. (Education Bureau Circular No. 6/2009). Government Printer.

Ford, C. E. (2012). Clarity in applied and interdisciplinary conversation analysis. Discourse Studies, 14, 507-513.

Fowers, B. J., \& Davidov, B. J. (2006). The virtue of multiculturalism: Personal transformation, character, and openness to the other. American Psychologist, 61, 581-594.

Foyn, T., Solomon, Y., \& Braathe, H. (2018). Clever girls' stories: The girl they call a nerd. Educational Studies in Mathematics, 98, 77-93.

Garcia, O., \& Li, W. (2014). Translanguaging: Language, bilingualism and education. Palgrave Macmillan.

Haider, S. (2019). Access to English in Pakistan: Inculcating prestige and leadership through instruction in elite schools. International Journal of Bilingual Education and Bilingualism, 22(7), 833-848.

Hammersley, M., \& Atkinson, P. (2007). Ethnography: Principles in practice. Routledge.

Hand, V. (2012). Seeing culture and power in mathematical learning: Toward a model of equitable instruction. Educational Studies in Mathematics, 80(1-2), 233-247.

Heath, C., \& Hindmarsh, J. (2002). Analysing interaction: Video, ethnography and situated conduct. In T. May (Ed.), Qualitative Research in Action (pp. 99-121). SAGE Publications.

Ho, W. Y. J., \& Li, W. (2019). Mobilising Learning: A translanguaging view. Chinese Semiotic Studies, 15(4), 533-559.

Hutchby, I., \& Wooffitt, R. (1998). Conversation analysis: Principles, practices and applications. Blackwell.

Jefferson, G. (2004). Glossary of transcript symbols with an introduction. In G. Lerner (Ed.), Conversation analysis: Studies from the first generation (pp. 14-31). John Benjamins.

Jegede, O., \& Aikenhead, S. (1999). Transcending cultural borders: Implications for science teaching. Research in Science \& Technology Education, 17(1), 45-66.

Kress, G. (2004). Reading images: Multimodality, representation and new media. Information Design Journal, $12,110-119$.

Kress, G. (2010). Multimodality: A social semiotic approach to contemporary communication. Routledge.

$\mathrm{Ku}, \mathrm{H}$., Chan, K., and Sandhu, K. (2005). A research report on the education of South Asian ethnic minority groups in Hong Kong. Centre for Social Policy Studies, Department of Applied Social Sciences, The Hong Kong Polytechnic University S.K.H. Lady MacLehose Centre.

Ladson-Billings, G. (1995). But that's just good teaching! The case for culturally-relevant pedagogy. Theory Into Practice, 34, 159-165.

Li, W. (2011). Moment analysis and translanguaging space: Discursive construction of identities by multilingual Chinese youth in Britain. Journal of Pragmatics, 43, 1222-1235.

Li, W. (2018). Translanguaging as a practical theory of language. Applied Linguistics, 39, 9-30.

Li, W. (2020). Multilingual English users’ linguistic innovation. World Englishes, 39(2), 236-248.

Lin, A. M. Y. (2006). Beyond linguistic purism in language-in-education policy and practice: Exploring bilingual pedagogies in a Hong Kong science classroom. Language and Education, 20, 287-305.

Lin, A. M. Y. (2013). Classroom code-switching: Three decades of research. Applied Linguistics Review, 4, 195218. 
Lin, A. M. Y. (2019). Theories of translanguaging and trans-semiotising: Implications for content-based education classrooms. International Journal of Bilingual Education and Bilingualism, 22(1), 5-16.

Lin, A. M. Y., \& He, P. (2017). Translanguaging as dynamic activity flows in CLIL classrooms. Journal of Language, Identity and Education, 16, 228-244.

Lin, A. M. Y., \& Wu, Y. (2015). May I speak Cantonese?-Co-constructing a scientific proof in an EFL junior secondary science classroom. International Journal of Bilingual Education and Bilingualism, 18, $289-305$.

Lo, Y. Y. (2014). L2 learning opportunities in different academic subjects in content-based instruction: Evidence in favour of conventional wisdom. Language and Education, 28(2), 141-160.

Lo, Y. Y. (2015). How much L1 is too much?-Teachers' language use in response to students' abilities and classroom interaction in CLIL. International Journal of Bilingual Education and Bilingualism, 18, $270-288$.

Lo, Y. Y., \& Lin, A. M. Y. (2018). Content and language integrated learning in Hong Kong. In A. Gao (Ed.), Second handbook of English language teaching. Springer.

Lo, Y. Y., \& Lin, A. M. Y. (2019). Teaching and learning and scaffolding in CLIL science classrooms. Journal of Immersion and Content-Based Language Education, 7(2), 151-165.

Macaro, E. (2018). English Medium Instruction. Oxford: Oxford University Press.

Markee, N., \& Kasper, G. (2004). Classroom talks: An introduction. Modern Language Journal, 88, 491-500.

Martin, J., Maton, K., \& Doran, Y. (2020). Accessing academic discourse: Systemic functional linguistics and legitimation code theory. Routledge.

Matsumoto, Y. (2018). At challenging but "learning" moments: Roles of nonverbal interactional resources for dealing with conflicts in English as a lingua franca classroom interactions. Linguistics and Education, 48, 35-51.

May, S. (2014). The multilingual turn: Implications for SLA, TESOL and bilingual education. Routledge.

Mazak, C., \& Herbas-Donoso, C. (2015). Translanguaging practices at a bilingual university: A case study of a science classroom. International Journal of Bilingual Education and Bilingualism, 18, 698-714.

McNeill, D. (1992). Hand and mind. University of Chicago Press.

Miles, S., \& Singal, N. (2010). The education for all and inclusive education debate: Conflict, contradiction or opportunity? International Journal of Inclusive Education, 14(1), 1-15.

Mondada, L. (2018). Multiple temporalities of language and body in interaction: Challenges for transcribing multimodality. Research on Language and Social Interaction, 51(1), 85-106.

Norris, S. (2004). Analyzing multimodal interaction: A methodological framework. Routledge.

O'Halloran, K. L. (2000). Classroom discourse in mathematics: A multisemiotic analysis. Linguistics and Education, 10(3), 359-388.

Phelan, P., Davidson, A., \& Cao, H. (1991). Students' multiple worlds: Negotiating the boundaries of family, peer, and school cultures. Anthropology and Education Quarterly, 22, 224-250.

Piliouras, P., \& Evangelou, O. (2012). Teachers' inclusive strategies to accommodate 5th grade pupils' crossing of cultural borders in two Greek multicultural science classrooms. Research in Science Education, 42, 329-351.

Poon, A. Y. K. (2010). Language use, language policy and planning in Hong Kong. Current Issues in Language Planning, 11(1), 1-66.

Pun, J. and Macaro, E. (2018). The effect of first and second language use on question types in English medium instruction science classrooms in Hong Kong. International Journal of Bilingual Education and Bilingualism, Epub ahead of print 1-14.

Roos, H. (2019). Inclusion in mathematics education: An ideology, a way of teaching, or both? Educational Studies in Mathematics, 100, 25-41.

Sahan, K., \& Rose, H. (2021). Problematising the E in EMI: Translanguaging as a pedagogic alternative to English-only hegemony in university contexts. In B. Paulsrud, Z. Tian, \& J. Toth (Eds.), English-medium instruction and translanguaging. Multilingual Matters.

Salend, S. J., \& Garrick-Duhaney, L. M. (1999). The impact of inclusion on students with and without disabilities and their educators. Remedial and Special Education, 20(2), 114-126.

Schensul, J. J., \& LeCompte, M. D. (2013). Essential ethnographic methods: A mixed methods approach. AltaMira Press.

Schleppegrell, M. (2004). The language of schooling: A functional linguistics perspective. Routledge.

Schleppegrell, M. (2007). The linguistic challenges of mathematics teaching and learning: A research review. Reading and Writing Quarterly, 23, 139-159.

Slee, R. (2004). Inclusive education: A framework for reform? In V. Heung \& M. Ainscow (Eds.), Inclusive education: A framework for reform? HK Institute of Education. 
Surgeon, W. (2007). Diversity and choice for children with complex needs. In R. Cigman (Ed.), Included or excluded? The challenge of the mainstream for some SEN children. Routledge.

Tai, K. W. H. and Li, Wei. (2020.) Bringing the Outside In: Connecting Students' Out-of-School Knowledge and Experience through Translanguaging in Hong Kong English Medium Instruction Mathematics Classes. System 95, 1-32.

Tai, K. W. H. and Li, Wei. (2021a). Constructing Playful Talk through Translanguaging in the English Medium Instruction Mathematics Classrooms. Applied Linguistics, 42(4), 607-640.

Tai, K. W. H. and Li, Wei. (2021b). Co-Learning in Hong Kong English Medium Instruction Mathematics Secondary Classrooms: A Translanguaging Perspective. Language and Education, 35(3), 241-267.

Tai, K. W. H. and Li, Wei. (2021c.). The Affordances of iPad for Constructing a Technology-Mediated Space in Hong Kong English Medium Instruction Secondary Classrooms: A Translanguaging View. Language Teaching Research. Epub ahead of Print.

ten Have, P. (1990). Methodological issues in conversation analysis. Bulletin de Méthodologie Sociologique, 27, $23-51$.

Tollefson, J., \& Tsui, A. B. M. (2014). Language diversity and language policy in educational access and equality. Review of Research in Education, 38, 189-214.

Trussler, S., \& Robinson, D. (2015). Inclusive practice in the primary school: A guide for teachers. Sage.

Tsang, S. C. S. (2021). An exploratory study of Chinese-as-an-additional-language teachers' agency in post-1997 Hong Kong: An ecological perspective. Current Issues in Language Planning, 22, 19-40.

Tsung, L., Cen, S., Qi, Y., \& Zhang, Q. (2012). Researches on Chinese language learning among minority students in Hong Kong: Theories, challenges and practices. Hong Kong University Press.

Waring, H. Z. (2008). Using explicit positive assessment in the language classroom: IRF, feedback, and learning opportunities. Modern Language Journal, 92, 577-594.

Waring, H. Z., \& Hruska, B. L. (2011). Getting and keeping Nora on board: A novice elementary ESOL student teacher's practices for lesson engagement. Linguistics and Education, 22, 441-455.

Williams, C. (1994). An evaluation of teaching and learning methods in the context of bilingual secondary education. PhD thesis, University of Wales.

Woodley, H. H. (2016). Balancing windows and mirrors: Translanguaging in a linguistically diverse classroom. In T. Kleyn \& O. García (Eds.), Translanguaging with multilingual students: Learning from classroom moments (pp. 83-100). Taylor and Francis.

Wu, Y., \& Lin, A. M. Y. (2019). Translanguaging and trans-semiotising in a CLIL biology class in Hong Kong: Whole body sense-making in the flow of knowledge co-making. Classroom Discourse, 10(3-4), 252-273.

Publisher's Note Springer Nature remains neutral with regard to jurisdictional claims in published maps and institutional affiliations.

Kevin W. H. Tai is a Doctoral Graduate in Applied Linguistics in the UCL Centre for Applied Linguistics at the UCL Institute of Education, University College London (UCL). Additionally, Kevin is also the Editorial Board Member and Editorial Assistant of the International Journal of Bilingual Education and Bilingualism (SSCIlisted Journal; Routledge) and The Language Learning Journal (ECIS-listed Journal; Routledge). He completed his doctoral coursework in Educational Research at the University of Cambridge, where he was Hughes Hall Hong Kong Alumni Scholar. He holds an MSc degree in Applied Linguistics and Second Language Acquisition with Distinction in Dissertation from the University of Oxford. Kevin is CELTA-qualified and his research interests include language education policy, classroom discourse, translanguaging in multilingual contexts and qualitative research methods (particularly Multimodal Conversation Analysis, Interpretative Phenomenological Analysis and Linguistic Ethnography). His research has appeared in international peer-reviewed journals, including Classroom Discourse (2018); Language and Teaching Research (2021). Language and Education (2019; 2021), Linguistics and Education (2019), System (2020a; 2020b), Applied Linguistics (2021), International Journal of Science Education (2021) and Language Teaching Research (2021). Kevin is a Fellow of the Royal Society of Arts (FRSA) and an Associate Fellow of the Higher Education Academy (AFHEA). 